\title{
Historia parlamentaria en la Guerra con Chile: la Asamblea de Cajamarca y el presidente regenerador Miguel Iglesias (1882 - 1883)
}

\author{
Julio Abanto Chani \\ juleo80@hotmail.com \\ Lugar de la Memoria (LUM)
}

\section{RESUMEN:}

La guerra con Chile (1879-1883) afectó el normal funcionamiento de las instituciones peruanas y el Congreso de la República no fue la excepción. En esta oportunidad, rescataremos la importancia de la Asamblea del Norte como principal brazo de apoyo del gobierno de Miguel Iglesias y secundando los intereses de los terratenientes serranos del norte por evitar la devastación de los circuitos económicos comerciales de esa región y la movilización campesina en los movimientos de resistencia, en total contraposición con los intereses salitreros de la burguesía limeña en Tarapacá. Este cuerpo legislativo tuvo que atender los conflictos suscitados por la ocupación chilena del país y las exorbitantes peticiones de paz que concluirán con la suscripción del Tratado de Ancón.

Palabras Clave: Guerra con Chile (1879-1883); Historia del Congreso de la República; Gobierno de Miguel Iglesias (1882-1883); Asamblea del Norte (1883); Mensajes a la Nación ante el Congreso de la República.

\section{Parliamentary history in the war with Chile: the Cajamarca Assembly and the regenerating president Miguel Iglesias (1882 - 1883)}

\begin{abstract}
:
The war with Chile (1879-1883) affected the normal functioning of Peruvian institutions and the Congress of the Republic was no exception. On this occasion, we will rescue the importance of the Northern Assembly as the main supporting arm of the government of Miguel Iglesias and supporting the interests of the northern landowners to avoid the devastation of the commercial economic circuits of that region and the peasant mobilization in the Movements of resistance, in total opposition to the nitrate interests of the Lima bourgeoisie in Tarapacá. This legislative body had to deal with the conflicts caused by the Chilean occupation of the country and the exorbitant petitions for peace that will conclude with the signing of the Treaty of Ancon.

Keywords: War with Chile (1879-1883); History of the Congress of the Republic; Government of Miguel Iglesias (1882-1883); Northern Assembly (1883); Messages to the Nation and the Congress of the Republic.
\end{abstract}

(C) Los autores. Este artículo es publicado por ISHRA, Revista del Instituto Seminario de Historia Rural Andina de la Facultad de Ciencias Sociales de la Universidad Nacional Mayor de San Marcos. Este es un artículo de acceso abierto, distribuido bajo los términos de la licencia Creative Commons Atribucion - No Comercia_ Compartir Igual 4.0 Internacional. (http://creativecommons.org/licenses/by-nc-sa/4.0/) que permite el uso no comercial, distribución y reproducción en cualquier medio, siempre que la obra original sea debidamente citada. 


\section{Introducción: el año 1882 y el contexto de la convocatoria}

Miguel Iglesias fue un poderoso terrateniente cajamarquino, conocido por el control de numerosas haciendas. ${ }^{1}$ Tuvo una activa participación en el ámbito regional como colaborador de las asonadas que organizó Nicolás de Piérola. Cuando este asumió el poder en diciembre de 1879 lo nombra secretario de Guerra y le encargó la defensa del Morro Solar, en las vísperas del ataque chileno a Lima. Se batió valerosamente en su punto de combate, llegando a perder a su hijo Alejandro. Es tomado prisionero y enviado como emisario ante el dictador, a quien le comunica que, en su sincera opinión, debía reconocer la victoria chilena antes que derramar más sangre peruana en una próxima batalla.

Tras la caída de la capital, Iglesias se retiró a su hacienda Udima² y no se involucró más en política. Convocado nuevamente en el mes de marzo de 1882 por el vicepresidente Montero, ejerció el cargo de jefe político superior militar del norte y confió en un pronto término de la guerra, pues el viaje del vicepresidente a Huaraz y su entrevista con el ministro norteamericano Trescot así lo garantizarían. La designación de Iglesias no cayó bien en todos los actores políticos regionales (Anónimo, 1886, p. 58-60). Por ello, sus primeras labores fueron la de sofocar los motines desencadenados por el viraje de Montero en noviembre de 1881, y su adhesión a García Calderón.

Los cabecillas de las montoneras fueron M. Becerra y José M. Puga. En el mes de abril ante el aumento de las operaciones de las montoneras, Iglesias se constituyó y dirigió personalmente una expedición para dispersar y arrestar a los amotinados. El prefecto Guillermo Serna, a cargo de la ciudad de Cajamarca, informó que la expedición punitiva perseguía en la provincia de Celendín a Puga, José Villanueva, Domingo Llerena con 10 acompañantes. ${ }^{3}$ Estos huyeron y se refugiaron en la hacienda La Pauca, fugando luego en diferentes direcciones y sin poder impedirlo el subprefecto. En Chota, se fragmentaban las fuerzas de Becerra e Iglesias volvía airoso a Cajamarca (Serna, 1882, s/f).

El otro problema que enfrentó Iglesias fue la alta probabilidad de un asalto chileno sobre Cajamarca. Desde inicios de 1882, la prefectura de Cajamarca recibió de forma incesante llamados de gobernadores y subprefectos que avisaban haber observado movimiento enemigo cerca de sus jurisdicciones. Recordemos que Chile ocupaba la costa norte con guarniciones permanentes desde febrero de 1881, siendo diezmadas por una epidemia de fiebre amarilla.

\footnotetext{
1 El objetivo de este artículo es trascender a la rápida calificación de «traidor» que se le brinda a Miguel Iglesias en su actuación durante la guerra. Al hacerlo, se anula la capacidad de examinar los aspectos que influenciaron su decisión de apartarse y perjudicar los esfuerzos de la resistencia de Cáceres en Junín, de las gestiones diplomáticas de Francisco García Calderón en Chile y de Lizardo Montero en Arequipa. Ello implica considerar el contexto nacional, regional y personal de este caudillo. No obstante, también debo precisar que este artículo no trata de eximir la responsabilidad de este caudillo.

2 Cajamarca fue la principal ciudad de la sierra norte para el siglo XIX y tuvo una dinámica diferenciada a la sierra central y sur, principalmente en cuanto a la distribución de la tierra, al papel de la hacienda, el vínculo entre el campo y la ciudad, y la relación de los terratenientes con las comunidades campesinas. $\mathrm{Ni}$ en el sur ni el norte se apreciaron movilizaciones campesinas como en el centro del país en el proceso de resistencia dirigido por Andrés A. Cáceres, y analizados por Nelson Manrique (1981, 1988) y Florencia Mallon (2003). Sin embargo, se hace necesario contar con mayores estudios para conocer el rol de las comunidades campesinas dentro de la vorágine social desatada por la guerra con Chile en Cajamarca y su participación dentro de la lucha de los caudillos regionales como Miguel Iglesias y José Mercedes Puga. Un conflicto social que se extendería hasta la misma guerra civil entre Cáceres e Iglesias (18841885).

3 Florencia Mallon (2003,435-452) propuso que el grupo que lideró Puga estuvo constituido por una alianza pluriclasista, pero que su plataforma de lucha no llegó a conformar una visión de nación como si lo llegó a formular, dentro de sus propios horizontes, las comunidades campesinas de la sierra central. La singularidad de lo que la guerra con Chile desató en los campesinos indígenas también fue estudiado por Nelson Manrique (1981, 375-389), agregando los componentes de clase y lo étnico. Ambos autores someterían los resultados de sus investigaciones hace unas décadas en un intenso e interesante debate con Heraclio Bonilla, siendo uno de sus episodios más emblemático el registrado en la Revista Andina con el artículo de Mallon «De ciudadano a "otro". Resistencia nacional, formación del estado y visiones campesinas sobre la nación en Junín» del año 1994.
} 
Iglesias puso un celo especial en el tratamiento de este tema para conocer realmente la exactitud de las afirmaciones de invasión solicitando datos fidedignos y colocando avanzadas sobre los puntos donde se apostarían los chilenos. En mayo de 1882, el subprefecto de Cajabamba comunicó los movimientos de las fuerzas chilenas provenientes de Trujillo. Se reafirmó esta noticia con los datos proporcionados por el gobernador de Huamachuco (Serna, 1882, s/f).

Al ser inminente una incursión enemiga, el prefecto Serna trasladó la prefectura hacia la provincia de Celendín, recogiendo en su retirada pertrechos y artículos del ejército sin previo conocimiento de Miguel Iglesias, quien al parecer no se encontraba en Cajamarca, desaprobando la retirada del prefecto por desguarnecer la ciudad (Serna, 1882, s/f). Serna indicó que sus tropas se encontraban a 10 días de marcha y en una situación deplorable. Además, no se contaban con los recursos y armas suficientes, quedando la corporación municipal como la única autoridad en la capital departamental (Serna, 1882, s/f).

Iglesias se mostró totalmente fastidiado por la resolución tomada por Serna, ya que al parecer creía que dejar la ciudad no era aún una posibilidad (Serna, 1882, s/f). Los soldados chilenos quedaron estacionados en el poblado de San Pablo y dos semanas después un piquete se internaría en la ciudad.

\section{La impaciencia de iglesias por la paz: entre la batalla de San Pablo y el «Grito de Montán»}

Iglesias estaba impaciente por lograr la paz. Su idea de paz incondicional, a todo trance y a cualquier costo había ido madurando junto con su feroz censura a los actos del almirante Montero, el civilismo y la burguesía limeña. Desde el mes de marzo de 1882, realiza esfuerzos por obtener una pronta paz con la colaboración de Maximiliano Frías y Julio Hernández.

Ambos eran redactores del diario cajamarquino La Reacción, donde formulan sus argumentos a favor de la paz, pero sobre todo destacan la idea de regeneración del Perú. Por ejemplo, en un comentario editorial, Hernández y Frías analizaron el pronunciamiento del Partido Nacional pierolista, emitido en Lima el 11 de febrero de 1882. Ambos son rotundos en su denuncia al civilismo por los males que sumieron al Perú en la bancarrota. Otro aspecto importante, es la crítica a cómo desde Lima se definían los destinos de las demás regiones, sin darles la oportunidad a opinar contra ese rígido centralismo que se iba perfilando por obra de la burguesía limeña.

Es hora de convencerse de que Lima libre, y mucho menos Lima esclava, no es el Perú: los departamentos tienen vidas, inteligencias y fuerzas propias para concurrir, sin tutela, a la realización de sus destinos (La Reacción, 1882, p. 1).

Este comentario editorial no fue nada grato para Montero. Al parecer fueron censurados por el gobierno en Huaraz, acusándolos de sediciosos, tal como lo denunció en agosto Miguel Iglesias. Para abril de 1882, Iglesias ya había presentado a Montero su renuncia irrevocable a la jefatura superior (Manifiesto de Montán. Cajamarca, 31 de agosto de 1882. En Guerrero, 1975, p. 67).

Ese mismo mes, Iglesias afirmó que en su decisión no había pesado en él egoísmo alguno ni intrigas de partido. Además, era un convencido de que el Perú debía firmar sin demora la paz y dedicarse a tiempo completo a su regeneración:

La unificación de la República era una necesidad inaplazable, perentoria. Se creyó que mi concurso, en condición determinada, podía contribuir a robustecerla, y mi patriotismo me dictó apoyar al gobierno que acababa de inaugurarse con el beneplácito unánime de 
la nación. La urgencia de ajustar la paz con Chile del mejor modo posible, y de que la República se levante unida y vigorosa para sacudirse de los pasados extravios y entrar de lleno en la senda regeneradora, se me presenta fuera de duda (Proclama del general Miguel Iglesias. Cajamarca, 01 de abril de 1882. En Ahumada, 1898, VII, p. 107).

Germinaba en Iglesias la necesidad de culminar cuanto antes el conflicto internacional, puesto que día a día se devastaban todos los recursos del departamento y dejaba exhausta a la economía regional. Ya no bastaban los discursos de paz, era preciso sondear la disposición de las fuerzas chilenas y esperar un posible avenimiento.

Sigilosamente comisionó en julio de 1882 una tarea delicada a Mariano Castro Zaldívar. Su misión fue averiguar la situación política en Lima y escudriñar la posición de la autoridad de ocupación chilena sobre el estado de las negociaciones de paz. Castro se hallaba unido por vínculos familiares a Miguel Iglesias, contando con su confianza y fue el brazo derecho que requería. Recibió el delicado nombramiento de agente confidencial ante el ministro chileno en Lima, Jovino Novoa. Al tener la seguridad de que Chile trataría sólo con Iglesias, prosiguieron con las conversaciones con Novoa y recibió el respaldo de las armas chilenas tanto en el despliegue para liquidar a las tropas de la resistencia como para lograr instalarse en Palacio de Gobierno (Memoria que el Delegado Mariano Castro presenta al Supremo Gobierno. Lima, 21 de octubre de 1883. En Ahumada, 1898, VIII, pp. 457 - 461).

Todo parece indicar que en Santiago simpatizaban con la idea de patrocinar nuevamente a un gobierno peruano que aceptase en todos sus términos sus onerosas demandas. Castro al igual que Iglesias, estaba convencido de que la paz era inevitable y que debía aceptar la derrota (Memoria que el Delegado Mariano Castro presenta al Supremo Gobierno. Lima, 21 de octubre de 1883. En Ahumada, 1898, VIII, p. 457). Novoa le comunicó al presidente Santa María cómo el norte escindiría la unidad política que hasta ese momento tenía el Perú y culminaría constituyéndose en la futura Asamblea del Norte:

Iglesias cree que Montero es un estorbo para la paz y que es indispensable cambiar el actual orden de cosas. Piensa que le sería fácil hacer que los pueblos del norte, donde no imperan nuestras armas declararan por medio de actas o comicios populares que desconocían el titulado gobierno de Huaraz, proclamando al mismo Iglesias como jefe supremo, investido de toda la suma de poder necesario para dar solución definitiva a la contienda. Cree también que si llegado el caso, se permite que vecinos de Lima y Callao se reúnan pacificamente para deliberar lo que al país convenga en estos momentos arribarán al mismo acuerdo de los pueblos del norte; para todo ello cuenta con el apoyo de los pierolistas. Tengo motivos para creer que en pocos días más me van a proponer privadamente la idea por conducto de don Mariano Castro Zaldivar, cuñado de Iglesias, y rico propietario del Norte (Carta de Jovino Novoa al presidente Santa María. Lima, 01 de agosto de 1882. En Bulnes, 1919, III, p. 361).

Sin embargo, cuando todo marchaba bien, algo sucedió: la batalla de San Pablo y el cúmulo de victorias peruanas en el centro desgarraron la jactancia enemiga. ${ }^{4}$ Por esta razón, Patricio Lynch aseveraba que «[...] a pesar de las instrucciones del Gobierno sobre Cajamarca, es indispensable

4 Es interesante comprobar que a pesar de obtener la victoria en Lima (enero de 1881) el fin de la guerra se hallaba distante y las victorias peruanas mostraron cuan vulnerables y frágiles eran las bases de la ocupación chilena y que todo el aparato desplegado de Chile en el Perú para cubrir el ámbito económico, diplomático y militar podía desplomarse y perderse de la noche a la mañana. Mejor graficadas no pueden estar estas preocupaciones en documentos recopilados en las Memorias de Patricio Lynch, los tomos de Pascual Ahumada y Bulnes, y recientemente el libro Chile en el Perú. La ocupación a través de sus documentos 1881-1884 de Carmen Mc Evoy. De ahí la ferocidad y rapidez por descabezar a la clase política representada en los partidos Civil y Nacional pierolista, apresando y confinando a sus líderes en Angol, sumándose al presidente García Calderón cautivo desde noviembre de 1881. Antes de sufrir toda la represalia chilena, Iglesias abdicó a todo esfuerzo de resistencia, asumiendo resignadamente la pérdida de Tarapacá. Provincia clave para los intereses de la burguesía limeña, pero no para él y su familia. 
tomar medidas serias y no he trepidado en ordenar este ataque» (Cablegrama del jefe del Ejército Chileno en el Perú, Patricio Lynch al ministro de Guerra. Lima, 26 de julio de 1882. En Ravines, 1992, p.129). La contraofensiva chilena por las derrotas en el centro del Perú fue implacable. Novoa sería el gestor para la identificación de los principales responsables, políticos (civilistas) proclives al gobierno de Lizardo Montero en Lima:

El movimiento obedece a planes concertados con gentes de Lima, sin duda y puesto que nuestra benevolencia nos da amargos frutos, creo que ha llegado el caso de obrar de otra manera. Me parece que en respuesta al asalto infame de que ha sido víctima la compañia de Chacabuco debemos elegir en Lima cien personas, y llevarlas a la prisión para remitirlas en el primer transporte. Convendría también imponer un cupo que no siendo insignificante pueda hacerse efectivo en aquellos que por su participación conviene que sientan los efectos de la situación que nos crean; de tomarse presos figurarían necesariamente Candamo, Elías y Varela, que son los agentes de Huaraz que dirigen la política en Lima (Telegrama de Jovino Novoa al presidente Santa María. Lima, 13 de julio de 1882. En Bulnes, 1919, III, p. 314).

El presidente Santa María aplicó con rigor estas medidas contra la resistencia peruana:

Es menester ahora tomar la revancha de una manera digna de nosotros, no con inútiles matanzas de indios, sino yendo más arriba a los instigadores, sin perjuicio de hacer sentir a los pueblos en que nuestras fuerzas han sido hostilizadas cruelmente todo el peso de nuestra venganza (Telegrama del presidente Santa María a Jovino Novoa. Santiago, 28 de julio de 1882. En Bulnes, 1919, III, p. 315).

Con esa autorización, Novoa y Lynch analizaron el panorama político y decidieron la suerte de los principales dirigentes en Lima del gobierno monterista, es decir, los miembros de la Delegación de Lima:

Anteanoche convinimos con Lynch la prisión de doce individuos conocidos y que los últimos sucesos aconsejaban asegurar. Indiqué que la pesquisa se hiciera a las siete de la mañana del día siguiente para encontrarlos a todos en su casa, pero ayer supe que el general había creído más acertado verificarla a las 11am. Consecuencia que varias andaban ya fuera y solo pudo tomarse a don José Antonio García y García, La Cotera, Elías y Candamo. Los que no fueron habidos pero que saben que los buscaban no serán tan tontos que vengan a presentarse (Carta de Jovino Novoa al presidente Santa María. Lima, 03 de agosto de 1882. En Bulnes, 1919, III, p. 316).

La sorpresiva derrota en San Pablo enfureció de sobremanera al Palacio de la Moneda (Lynch, 1884, pp. 375-377; Ravines, 1992, pp. 412-415). Iglesias comprendía perfectamente que debía realizar gestos significativos para recuperar la atención chilena y demostrarles que su intención iba en serio. Por eso, el 31 de agosto de 1882, cuando Montero ingresaba a Arequipa, Iglesias proclamó en su hacienda el Grito de Montán, manifiesto por el cual se señaló explícitamente la necesidad de ajustar una paz a cualquier costo para finalizar cuanto antes la guerra. La cesión de Tarapacá fue crucial en su declaración: su virtual pérdida representaba un sacrificio inevitable y simbolizó «[...] un pedazo de terreno, que representa un puñado de oro, fuente de nuestra pasada corrupción» (Manifiesto de Montán. Cajamarca, 31 de agosto de 1882. En Guerrero, 1975, p. 70); siendo una abierta ruptura con el gobierno de Montero, las gestiones de García Calderón, y la lucha titánica de Cáceres.

Si le pedíamos a Iglesias ser explícito y directo, con la proclama de Montán detalló más su pensamiento. Ubicó a un Perú escarnecido y humillado por las huestes chilenas, lo que hace que 
su conciencia le ofrezca su auxilio para levantar la nacionalidad peruana. Deploraba la guerra civil entre García Calderón y Piérola. Aceptó contribuir a la unidad cooperando con el vicepresidente Montero. Pero este le decepcionó al «[...] echarse en brazos del círculo que ha trabajado con el mayor tesón por la ruina nacional». Censura al civilismo y juzga duramente al pierolismo, cantera política de la que proviene, por no dar la talla en la hora suprema y estar afiebrada en la inicua idea de proseguir la guerra. Estos comportamientos hacen que no milite en ninguno de los mencionados partidos y los critica de forma feroz: « $i \mathrm{~A} h !_{j}$ Guerreros de gabinete, patriotas de taberna, zurcidores de intrigas infernales! ¡Cobardes, mil veces cobardes, autores de la catástrofe nacional!» (Manifiesto de Montán. Cajamarca, 31 de agosto de 1882. En Guerrero, 1975, p. 70).

Muchas preguntas se tejieron sobre las verdaderas razones que impulsaron a Iglesias a ser partidario de la paz a todo trance, aun al terrible costo de la mutilación territorial y esbozando una identidad propia que lo diferenciaría del civilismo y del pierolismo. En ellas, posiblemente pesaron la devastación del circuito económico regional del norte, que integraba Cajamarca con sus productos agropecuarios y mano de obra en las azucareras de los departamentos costeños de La Libertad y Lambayeque. De otro lado, para Iglesias la movilización campesina en el centro del país en el marco de la lucha por la resistencia era un pésimo ejemplo para las comunidades del norte (Abanto, 2012, p. 186). En palabras de Nelson Manrique, con Iglesias se produjo una importante movilización terrateniente que entró en abierta pugna con los intereses de la burguesía limeña, que trató de retener Tarapacá, no sólo por un sentimiento patrio sino porque toda la fuente de su hegemonía socioeconómica se sustentó en esa provincia sureña y sus ricas salitreras (Manrique, 1988, pp.137-146)

Los chilenos se encontraban desengañados de los políticos peruanos y la paz era una idea cada vez más lejana. Montero partía robustecido hacía Arequipa con un nuevo ejército en el sur y en el centro había otro al mando de Cáceres. Por su parte, García Calderón iniciaba una serie de conversaciones con el presidente Santa María para definir el destino de Tarapacá, contando con la presión favorable a Chile del ministro americano Cornelius Logan.

En ese escenario, Iglesias aún tenía la potente imagen de ser una pieza más del pierolismo, al que los chilenos tampoco daban credibilidad y obviamente era materia de suspicacia de parte de Novoa:

La actitud del pierolismo con Iglesias merece ser tratada aparte. Iglesias salía de su seno. Su vida política estaba adherida a ese partido. Recibió instigaciones de sus coopartidarios de Lima para rebelarse contra el gobierno de Montero y proclamar la paz. Así se lo anunció Novoa a Santa María en agosto [...]. Dudaba que fuera un gesto de patriotismo de verdad, de condenación de todo el pasado por igual; la evocación de un Perú nuevo, con igual anatema para sus partidarios y caudillos. El que lo dijera así su manifiesto nada valía para él. Y no creyéndolo Novoa lo estimaba como el caudillo de un partido, empujado y apoyado por él. Y bajo su punto de vista chileno la celebraba. Deseaba que el asumía esa actitud tuviese detrás una agrupación política para que sus propósitos no cayeran en el vacío. (Bulnes, 1919, III, p. 357)

Para avanzar con las negociaciones y construir confianza en el mando chileno, Iglesias dio el siguiente paso convocando a la Asamblea del Norte, que no estuvo exento de dificultades. En otras palabras, la Asamblea de Cajamarca se constituyó como parte del plan de paz que trazó Iglesias para ganarse la atención y confianza de La Moneda. Julio Hernández, uno de los hombres de Iglesias y convertido en el nuevo secretario de la jefatura del norte, reforzó las ideas esgrimidas por el hacendado cajamarquino: 
El Manifiesto datado en Montán a 31 de agosto y el decreto de convocatoria a elecciones de 16 del mes siguiente, creaban en la región del norte un nuevo orden político, de tan grandes trascendencias para la suerte del Perú, como de difícil dirección y desarrollo, dadas las circunstancias generales de la República y especiales del Norte, que todos vosotros conocisteis y que apreciareis debidamente. El Manifiesto de Montán, a que ya me he referido, pone punto a tantas desventuras, abriendo una nueva era al país al provocar una revolución radical, único medio posible para salvarlo del enemigo exterior y de la completa desorganización interna (Congreso de la República, 1883).

\section{III.Las dificultades para la instalación de la Asamblea}

La Asamblea del Norte fue convocada por el Manifiesto de Montán para el mes de noviembre, pero recién se pudo reunir el mes siguiente, exactamente el día de la Navidad y se extiende hasta los primeros meses de 1883. Tanto en su inauguración (diciembre de 1882) como en su clausura (abril de 1883) se realizaron proclamas a la Nación para informar de sus avances o conclusiones. A pesar de ello, tuvo serias resistencias y oposición de muchas regiones del país. ${ }^{5}$

Para la realización de las elecciones abundaron los terratenientes del norte ligados a la familia Iglesias. Por ejemplo, observamos como el prefecto de Cajamarca, por orden expresa del aún jefe superior del norte, instruyó a los subprefectos y gobernadores de su jurisdicción sobre la composición y elección de los asambleístas. Asimismo, se indicó que la caja fiscal sortearía los gastos para la venida de los diputados a la ciudad de Cajamarca:

Insinúe a sus administradores que procuren fijarse en personas honorables, de reconocido patriotismo y ajenas a la lucha de pasiones politicas que aniquila al país para confiarles el sagrado de su representación y en cuanto sea compatible con la libertad electoral, que la elección recaiga en personas todas de su mismo partido militante (Callirgos, 1882, s/f).

Apartado definitivamente de la senda trazada por el gobierno civilista, Iglesias empezó a difundir el mensaje de regeneración y paz exterior del bloque terrateniente a los prefectos y funcionarios de su dependencia, como jefe superior del norte y como tal comunicó los cambios que han de producirse, pero no todos se plegaron a su discurso. Ocurrieron protestas por el accionar iglesista en las ciudades de Huaraz (16 de octubre de 1882), Cajabamba (18 de octubre de 1882), Tarma (20 de octubre de 1882), Cerro de Pasco (20 de octubre de 1882), Huari (20 de octubre de 1882) (En Ahumada, 1898, VII, pp. 390-400). Iglesias trató de apaciguar los ánimos utilizando como pararrayos a un hombre trascendental en su ascenso y que lo acompañó en la génesis de su gobierno y lo seguirá hasta el fin de sus días en el poder: Julio Hernández, quien tuvo que aplacar la avalancha de reprobaciones (Circular del secretario de la jefatura superior política militar del norte, Julio Hernández a los prefectos del norte. Cajamarca, 25 de octubre de 1882. En Ahumada, 1898, VII, p. 390).

Para ese entonces aún arreciaba la figura de Piérola como posible interlocutor con Chile. Pero luego de sus declaraciones y visita a los Estados Unidos retornaría a Europa, retrasando

\footnotetext{
5 La historia parlamentaria es un eje de estudio que todavía tiene escasos trabajos en nuestro país y faltan más investigaciones sobre la historia de las instituciones como el Ejército, el Poder Judicial, etc. Y es que nuestra actual coyuntura nos muestra que se hace necesario contar con más investigaciones sobre los conflictos entre los poderes del Estado (Ejecutivo y Legislativo, en especial) y su influencia en la eficacia de la gobernabilidad en los siglos XIX y XX para recoger sus experiencias y aprendizajes en nuestros días. Para el caso específico de la guerra con Chile y la Asamblea de Cajamarca, debemos considerar que para tomar la decisión de la envergadura que ofrecía Iglesias (separarse del gobierno nacional establecido en Arequipa y entregar Tarapacá a los chilenos) requería una representación nacional que le entregase los poderes para suscribir una paz en las condiciones más lesivas para el país y que tendrían para él un alto costo político que implicarían su misma desaparición como caudillo o protagonista en la arena política en los años siguientes. En este caso, la Asamblea del Norte sirvió como mecanismo legal para brindar la legitimidad (totalmente puesta en entredicho) a los acuerdos que tomaría este cuerpo legislativo y que Iglesias adoptase en el futuro. En este caso, básicamente lo que se hacía era «guardar las formas» antes de firmar el protocolo de mayo de 1883 y finalmente el tratado de Ancón.
} 
su retorno al Perú y la dirección del pierolismo que se encontraba desorientado entre apoyar a Iglesias o mantenerse en su posición de abstención. Sin embargo, la condena principal al proceder de Iglesias se plasmó en la movilización de hombres que realiza José Mercedes Puga, su encarnizado rival en Cajamarca. Atizadas las divergencias con los Iglesias, Puga no trepidará en malograrle la fiesta y obstaculizarle la reunión de su asamblea en la ciudad. Opinó sobre el Grito de Montán:

Semejante documento en que Iglesias declaraba categóricamente que se rebelaba contra el gobierno constitucional que le habia delegado sus poderes y depositado toda su confianza; en que declaraba abiertamente la intención de entrar en connivencias con los chilenos y negociar con ellos la desmembración del territorio nacional, produjo el escándalo en toda la república y la excitación de todo pecho verdaderamente peruano. (Anónimo, 1886, p. 62).

Sin embargo, las huestes de Puga fueron rechazadas y se retiraron hacia Hualgayoc (Callirgos, 1882, s/f). El prefecto Callirgos, sucesor de Guillermo Serna, informa la dispersión de las fuerzas del hacendado de La Pauca. Tal noticia fue confirmada por el secretario de la jefatura, Julio Hernández, agregando que la montonera de Puga fue batida el 17 de noviembre de 1882:

Al fin, el día 15 de noviembre, los rebeldes se presentaron a las puertas de esta capital, con ánimo de atacarla tan luego como el pueblo los secundase, cediendo a las sugestiones que se ponían en práctica para apartarle de la causa que con tanta fe ha abrazado. Felizmente, unánime la opinión pública, condenó la actitud de los rebeldes; y en la tarde del 17 del mismo noviembre, fueron completamente batidos y dispersados en las posiciones de Carambayoc y Agomarca (Congreso de la República, 1883).

No obstante, esta victoria iglesista no logró que la Asamblea se reuniese en noviembre, mes señalado en la convocatoria. La Asamblea se reúne en juntas preparatorias desde el 8 de diciembre, siendo el día de la Navidad cuando inició oficialmente sus sesiones. Éstas son dirigidas por el vicepresidente Vidal García y García, por la ausencia de su electo presidente monseñor Risco, obispo de Chachapoyas. ${ }^{6}$ A pesar de la búsqueda bibliográfica no disponemos de mayor información sobre las juntas preparatorias y elección de representantes. Tampoco existe alguna edición del Diario de Debates (Dammert, 1983, p. 99). De acuerdo a Fernando Tuesta (2001, p. 141), la Asamblea de Montán quedó conformada de la siguiente manera:

Amazonas

Por Chachapoyas: Carlos Chocano Risco, Santiago Rodríguez

Áncash

Por Huaraz: José Silva Santisteban

Por Huari: Lorenzo Iglesias

Por Huaylas: Manuel Nicolás Corpancho

Por Pallasca: Clemente Arana

Por Pomabamba: Manuel Julio Rivera

6 Vidal García y García tuvo vínculos de familia con Miguel Iglesias y tuvo un rol protagónico en su gobierno. No solo fue el virtual presidente de la Asamblea de Cajamarca, sino también Delegado de este régimen en los departamentos del norte una vez que Iglesias firmó el protocolo de mayo de 1883, base de las condiciones onerosas de paz impuestas por Chile. Operó en Trujillo desde junio de 1883 esperando la venida del presidente Iglesias, quien paradójicamente no pudo trasladarse a dicha ciudad porque no contaba ni con los medios ni con las fuerzas militares para hacer un viaje hacia la costa. Recién con el desastre de la batalla de Huamachuco, Iglesias pudo arribar a Trujillo (1 de setiembre de 1883). Vidal García y García fue nombrado en 1884 como el nuevo ministro plenipotenciario del Perú en Chile, como parte de la reanudación de las relaciones diplomáticas, rotas en abril de 1879. 
Cajamarca

Por Cajamarca: Manuel Francisco Burga y Mariano Castro Zaldívar

Por Celendín: Mariano Burga

Por Chota: Roberto Osores

Por Contumazá: Francisco Placencia

Por Hualgayoc: Cruz Novoa

Por Jaén: Jerónimo Zevallos

La Libertad

Por Huamachuco: José Seijas

Por Otuzco: Julián Rojas

Por Pacasmayo: Gabriel Muñoz

Por Pataz: Francisco Posada

Por Trujillo: Manuel Pastor

Lambayeque

Por Chiclayo: Manuel Revilla, Santiago Vásquez

Loreto

Por Alto Amazonas: Juan Tirado

Por Bajo Amazonas: Adolfo Salmón

Piura

Por Huancabamba: Antonio Espinoza

Por Piura: Julio Hernández

San Martín

Por Moyobamba: Juan Caso y Vidal García y García

Por San Martín: Pedro Urrunaga y José Urteaga

Tumbes

Por Tumbes: Leopoldo Santolalla

Con la instalación de la Asamblea se cumplía con el primer objetivo del plan iglesista: garantizar la firma de paz. ${ }^{7}$ Finalmente, la Mesa Directiva de la Asamblea del Norte se constituyó de la siguiente forma (Congreso de la República, 1998, p. 63):

a. Presidente: Vidal García y García

b. Secretarios: Segundo Bringas y Santiago Rodríguez

\footnotetext{
7 Gracias a los documentos de la Sala para Investigadores de Manuscritos y Libros Raros de la Biblioteca Nacional del Perú, pudimos encontrar un valioso documento que se ha colocado como anexo del presente artículo y que muestra una faceta poco conocida de la historia parlamentaria en el Perú: el pago que realiza un cuerpo legislativo a sus miembros por concepto de traslado desde sus ciudades de origen o donde fueron proclamados como ganadores en las elecciones. Esto vendría a ser el antecedente de lo que conocemos como «gastos de instalación» presente en el Congreso de la República de nuestros días.
} 


\section{La producción legislativa de la Asamblea de Cajamarca}

Iglesias fue nombrado Presidente Regenerador de la República y en la práctica operó como un nuevo gobierno de facto que intentó diferenciarse de Montero y los pierolistas, cuyo líder se encontraba en Europa. Veamos ahora las principales iniciativas legislativas aprobadas por la Asamblea del Norte (Congreso de la República, 2015):

18. Aceptando la dimisión del general D. Miguel Iglesias, aprobada el 25 diciembre de 1882.

19. Confiriendo un voto de gracias al general de brigada Miguel Iglesias, aprobada el 25 diciembre de 1882 (Iglesias, 1883, s/f).

20. Decidiendo la paz inmediata con la República de Chile, siempre que las condiciones impuestas por el vencedor no sean tales que amenacen la independencia nacional, ni cieguen lo absoluto de las fuentes de su regeneración y progreso (Asamblea del Norte. Cajamarca, 29 diciembre de 1882. En Ahumada, 1898, VII, p. 402). Fue aprobada el 29 diciembre de 1882 (Bulnes, 1919, III, p. 359).

21. Constituyendo el Supremo Poder Ejecutivo Nacional, aprobada el 30 diciembre de 1882.

22. Eligiendo Presidente Regenerador de la República al General D. Miguel Iglesias, aprobada el 30 diciembre de 1882. En la sesión del 29 de diciembre se sometió a discusión la moción de la Comisión de Legislación integrada por los diputados Salmón, Castro Zaldívar y Santillán y que sería aprobada más adelante por unanimidad:

La paz es de absoluta necesidad al Perú. Debemos buscarla y obtenerla sin pérdida de momento en las mejores condiciones posibles, dada la angustiosa situación a que nos ha traído el éxito. Las condiciones que el Perú puede aceptar, no son ni pueden ser materia de discusión a priori. La victoria las impone; la razón y el patriotismo verdadero las pesan y las admiten (Asamblea del Norte. Cajamarca, 29 de diciembre de 1882. En Ahumada, 1898, VII, p. 398).

23. Disponiendo que la Asamblea del Norte admita en su seno a representantes de las provincias del centro y sur de la República, aprobada el 30 diciembre de 1882. Esta ley no tendría nada de extraño sino fuera por la participación y convergencia entre los intereses de Iglesias con las del principal terrateniente del centro del país, como lo fue Luis M. Duarte. De acuerdo a las fuentes revisadas, no hubo mayor acogida a esta convocatoria. Y es que no se recordaba una reunión legislativa de carácter regional desde que se constituyó el Estado Norperuano como parte de la Confederación Perú Boliviana el 06 de agosto de 1836 (Congreso de la República, 1836).

24. Las autoridades legales en los departamentos del norte los son únicamente si son establecidas por la Asamblea. Asimismo, se autorizaba al Supremo Gobierno a que se declare el estado de sitio en las zonas donde se subvirtiese el orden público. Aprobada el 5 de enero de 1883 (Asamblea del Norte, 1883, s/f). Al parecer esta disposición fue admitida a discusión debido a las acciones de hostigamiento emprendidas por José M. Puga.

25. Aprobación del Estatuto Provisorio, aprobada el 30 de enero de 1883 (Ugarte del Pino, 1978, pp. 377-378). Para la aprobación de esta ley no sólo se tuvo en cuenta el establecimiento de un marco normativo que lo distinguiese de la Constitución de $1860 \mathrm{y}$ del Estatuto pierolista de 1880. Se resaltó la necesidad de regular las garantías personales, 
por lo que con carácter de prioritario el Ministro General, Lorenzo Iglesias solicitó a la Asamblea «[...] contraerse de preferencia su atención a este pedido, que a nombre del Presidente Regenerador y por su orden tengo la honra de dejarlo indicado» (Iglesias, $1883, \mathrm{~s} / \mathrm{f})$.

26. Ley Orgánica Provisional de Municipalidades, aprobada el 28 de marzo de 1883. Esta ley pudo haber tomado en consideración la posición inicial del movimiento gestado por Luis M. Duarte en la municipalidad de Concepción (Junín) al proclamar unilateralmente la paz para arribar un acuerdo de paz independiente del gobierno provisorio de García Calderón y a la vez evitar las represalias chilenas por la lucha de resistencia que impulsaba Cáceres.

a. Ley expedida por la soberana asamblea del norte elevando al rango de distrito el caserío de Huacapampa, provincia de Celendín. Los diputados Mariano Burga, Pablo Santillán y Luis Salazar proponen el 15 de enero de 1883 elevar a Huacampampa de caserío a distrito en la provincia de Celendín. La proposición fue derivada a la Comisión de Demarcación (Asamblea del Norte, 1883, s/f). El 13 de febrero de 1883 fue aprobada la ley. Sus límites serían: por el oriente por la cima del cerro nombrado Chuchun, por el norte con las alturas de las colinas de Bacon que conducen en línea recta al cerro de Rundocusma, por el occidente con el camino que conduce a Cajamarca, y por el sur con el camino y río del Huanco en línea recta hasta Congat, encontrándose con el cerro referido de Chuchun y con la anexión de las aldeas de Cusichan, Tambo y Tingo (Asamblea del Norte, 1883, s/f). Al parecer esta ley iba de la mano con la obtención de mayores simpatías en la región y en una de sus principales provincias.

De otro lado, en la Asamblea del Norte también se discutieron asuntos de materia económica, a pesar de la estrechez del erario fiscal. No obstante, este tema en la producción legislativa fue sumamente específico y se refirió a la habilitación de caletas en el litoral de la costa norte para permitir un mayor tráfico marítimo entre ellos, por lo que el Ministerio General propuso la creación de un puerto menor en la ensenada de Ramazón (Sechura - Piura) y se evaluase la apertura de otras (Iglesias, 1883, s/f). Al parecer esta moción no fue aprobada.

Otros asuntos de mayor envergadura como la deuda externa o el salitre no fueron abordados por la Asamblea por lo limitado de sus poderes al no encontrarse completa la representación nacional en un Congreso y por la debilidad inicial con la que nace el gobierno de Iglesias, circunscrito solamente a Cajamarca.

\section{Composición política de la Asamblea del Norte}

La Asamblea del Norte se encontraba compuesta por representantes del norte de la República que incluía a los departamentos de Piura, Áncash, Loreto, La Libertad, Lambayeque y San Martín. La Asamblea era controlada por la facción terrateniente adicta a Iglesias. Se enfrentaron con total supremacía contra algunos civilistas como el representante Urteaga en los debates del Pleno. Urteaga declaró que Manuel Pardo fue el mejor gobernante de la historia del Perú debatiendo con Julio Hernández, el mejor cuadro político de Iglesias. La forma cómo reaccionaría Hernández dejó en claro que en Cajamarca no había espacio para escuchar las propuestas del civilismo. Transcribimos las líneas correspondientes al debate entre ambos legisladores:

URTEAGA: El gobierno de Manuel Pardo, que es el más glorioso de que ha tenido la república y lo declaro solemnemente ante esta cámara, fue un gobierno de iniciación, porque sin alcanzar la regeneración del país, deja el solio del poder empobrecido al general 
Prado. Y como castigo de esta cadena de disensiones intestinas, nos ha enviado el destino la más tremenda guerra en que nos hayamos empeñados; porque era necesario que los horrores de una cruel expiación nos llamasen a juicio y nos pidiera cuenta de nuestros tristes desvíos, de nuestros pasados errores.

HERNANDEZ: Ah! Excelentísimo Señor, ¿por qué ha querido el elocuente diputado lanzar en estos momentos tan imprudente y falsa apología? No necesitamos señor, remontarnos a la imbecilidad de San Martín ni al cesarismo de Bolivar, para encontrar las causas verdaderas, inmediatas de la guerra y consiguientes de nuestros desastres, humillación y miserias, Chile, hasta 1872 era nuestro aliado; hasta 1870 éramos más poderosos que Chile. ¿Quién nos hizo débiles por la enemistad maniatados? El señor Pardo [...] suscribió el tratado de alianza con Bolivia, decretó la expropiación de las salitreras y preparó la sucesión de Prado en el ejercicio del poder supremo.

Y como si no fuera bastante esperar el peligro como un idiota, el más glorioso gobierno que ha tenido el Perú, hirió de muerte a la industria chilena en Tarapacá. Para satisfacer impuras necesidades de círculo [...]. ¿Y este es el más glorioso gobierno que ha tenido el Perú? ¡Vergüenza! ¡Vergüenza! (Sesión de la Asamblea del Norte. Cajamarca, diciembre de 1882. En Ahumada, 1898, VII, pp. 400 - 401).

Pero, ¿quién era este hombre que brindaba las líneas señeras del futuro régimen iglesista desde la prensa, como secretario personal, asesor en la Jefatura del Norte, como agente confidencial y parlamentario? Si dentro del régimen iglesista, Manuel Castro Zaldívar operaba el aparato logístico y José Antonio de Lavalle el tema diplomático, Julio Hernández se encargaría del tratamiento de los debates y asuntos políticos, era el cerebro del entramado político. Fue secretario de la jefatura del norte entre el 20 de setiembre y el 8 de diciembre de 1882 . Veló por la reunión de la asamblea legislativa regional y la debelación de los rebeldes capitaneados por los opositores a Iglesias. Fue sustentador del nuevo orden de cosas y protagonista de la Asamblea del Norte, que nominó a Iglesias como nuevo presidente de la República. En la capital, su labor febril lo convierte en el motor de la instalación de la Asamblea Constituyente en 1884 y fue promotor del naciente Partido de Montán.

No fue el único altercado que tuvo Hernández. El diputado Cruz Novoa le interpuso una denuncia y pidió su prisión por desconocer la autoridad de la Asamblea y difundir un acuerdo en un impreso utilizando la Imprenta del Estado, en enero de 1883. Para ese mes, Hernández había sido nombrado oficial mayor del Ministerio de Relaciones Exteriores y había dejado de participar como asambleísta. El ministro general Lorenzo Iglesias recibió la denuncia y solicitó su descargo al oficial mayor. Hernández lo hace y declaró que no desconoció los acuerdos de la Asamblea y que la publicación fue personal, particular. Iglesias señaló que no hubo delito y la Asamblea, finalmente, absolvió al diputado acusado el 23 de enero de 1883 por la Comisión de Infracciones Norte, 1883, s/f).

Hernández no estuvo solo. En Lima, Iglesias contaba con la valiosa colaboración de otra figura: Luis M. Duarte, quien se encargaría de recoger adeptos para la futura aventura de tomar el poder. ¿Quién era este personaje? Duarte fue un pudiente terrateniente de Junín y dueño de numerosas haciendas en esa región. Como parte del pierolismo en 1880 fue nombrado subprefecto de Jauja y se le otorgó el grado de coronel con cargo a conformar una división a su mando, con tropas provenientes de Junín, Ayacucho y Huancavelica (Secretaría General de Estado, 1880, s/f). Pero luego se apartará de Piérola, al disentir con sus órdenes en la defensa de la capital. 


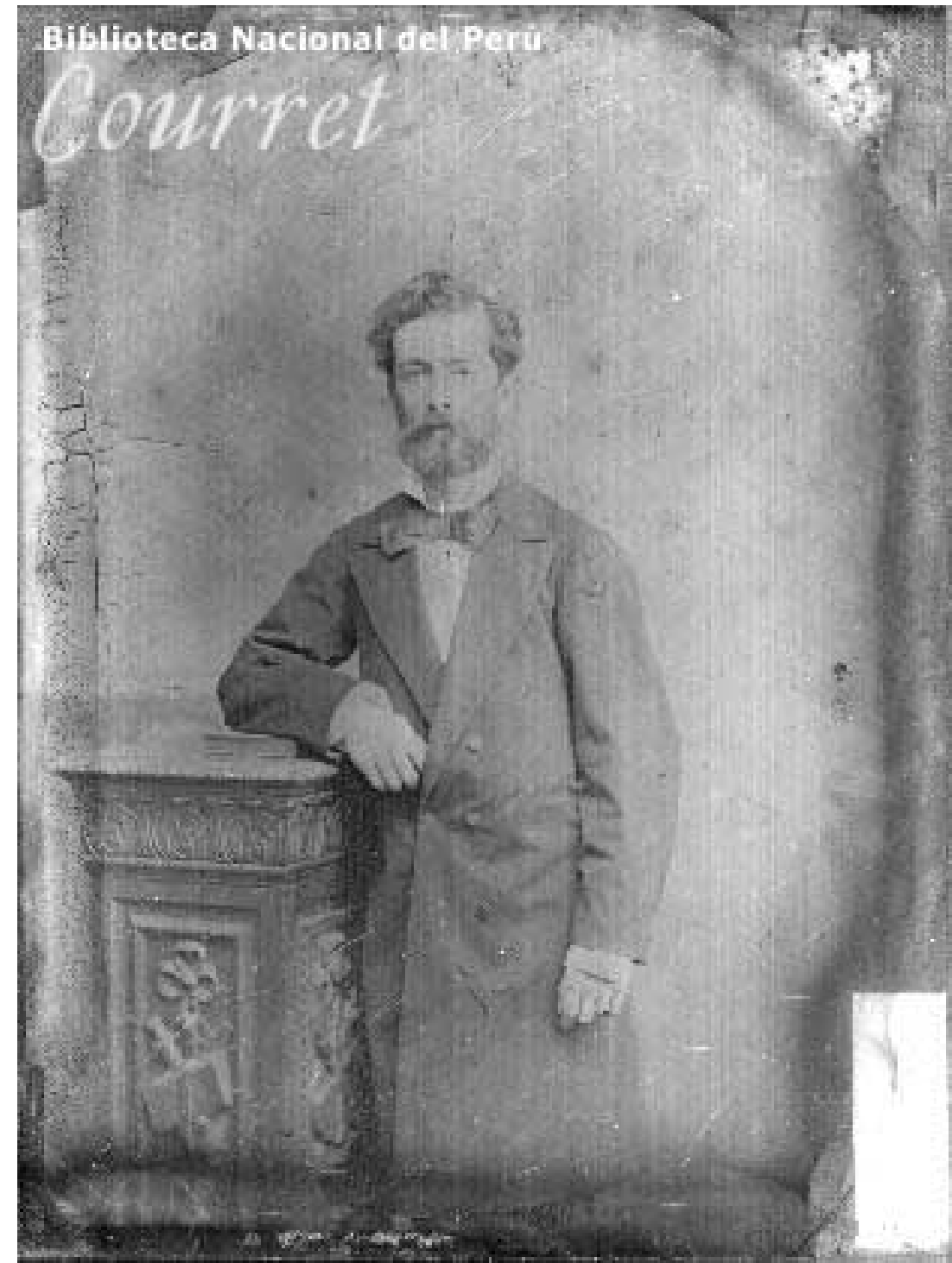

Fotografía $\mathbf{N}^{\circ}$ 01: Julio Hernández. Fue diputado por Piura en la Asamblea del Norte, siendo el principal operador político de Iglesias en Lima junto a Mariano Castro Zaldívar y José Antonio Lavalle. Fotografía tomada de la Colección Courret de la Biblioteca Nacional del Perú.

Al igual que Iglesias, se encontraba totalmente convencido de la inutilidad de tomar las armas y de resistir al invasor extranjero. Como alcalde de Concepción sugirió en 1882 al coronel Estanislao del Canto, jefe de la división expedicionaria chilena en la sierra central, que la corporación municipal que él presidía, realizaría una declaración que reconociera la derrota peruana y haría un llamado a desistir a todo tipo de movilización armada. No obstante, las victorias peruanas en Concepción, Pucará y Marcavalle, terminaron por expulsar las fuerzas de Del Canto de Junín (Manrique, 1988, p. 36) y se descartó la idea por el momento.

A pesar de este revés, Duarte viajó a Lima y en unión a Castro Zaldívar, agente de Iglesias, tramaron el hilo conductor que derivó en la conformación de un nuevo gobierno, de rendición incondicional. Castro Zaldívar reconocía los aportes de Duarte, aunque este manifestaba también un carácter indiscreto e impulsivo que podría ser fatal en el futuro. Junto a Jovino Novoa le aconsejaron prudencia. Elevado por la Asamblea del Norte como Presidente Regenerador, Iglesias lo nombró como jefe político y militar del centro (Lynch, 1884, p. 124) y parte hacia Huancayo a ocupar dicho cargo. Tropezará con varias dificultades hasta la victoria chilena en 
Huamachuco, cuando la correlación de fuerzas se hizo más favorable. Cuando retornó a Junín, las fuerzas chilenas «habían abrigado la esperanza» de que Duarte, representante del gobierno peruano, por medio de sus influencias en aquellos lugares, evitaría tan doloroso sacrificio atrayendo pacíficamente a los indios (Lynch, 1884, p. 155). Tan crucial se consideraba a Duarte que para agosto de 1883 fue vital para lograr la pacificación de la sierra central y la liquidación de las fuerzas caceristas, gracias al apoyo y auxilio a la expedición chilena Arriagada, jefe que se pronunció:

El día 5 llegué a Huallanca, encontrándome con las fuerzas del coronel Canto un tanto restablecidas de su fatiga. Una jornada antes, recibí comunicaciones del señor Luis $M$. Duarte, que, en el carácter de delegado del Gobierno de Iglesias, ha acompañado a esta División durante todo el tiempo de sus operaciones. Interesado el señor Duarte en nuestro buen suceso, ponía de su parte cuanto empeño era posible para adquirir datos convenientes y seguros sobre el paradero e intenciones de Cáceres, contando para ello con las autoridades y vecinos respetables de las localidades que, adhiriéndose a su representación, ponían sus servicios a disposición de la División Pacificadora (Oficio de la Comandancia en jefe de las Fuerzas Expedicionarias al Interior a Patricio Lynch. Lima, 06 de agosto de 1883. En Patricio Lynch, 1884, anexos).

No obstante, producto de la agudización y la polarización producida por la guerra civil, Duarte muere asesinado en 1884 en una situación aún no aclarada hasta el día de hoy (Pereyra, 2010, pp. 208-218).

Hay que recordar que Duarte había perdido varias haciendas en manos de las guerrillas campesinas y el ejército cacerista de resistencia. La guerra había sido completamente desastrosa para sus intereses. La amenaza social que significaba que los indígenas armados circularan en sus haciendas primó en su decisión en su instinto de preservación social. Si esta movilización pasaba en el centro del país, ¿era posible que ocurriese también en el norte, cuna del iglesismo?

Constante víctima de la lucha encarnizada entre los que quieren la prolongación o el fin de las calamidades públicas, he sido ejemplo de firme decisión por la paz. Tengo, pues, derecho a hablar por la salvación de mi país. Si el gobierno de Chile quiere la paz, debe retirar las tropas del norte, para rodear de prestigio el principio proclamado por Iglesias. La convocatoria del congreso debe ser franca y resueltamente bajo la base de la cesión absoluta de Tarapacá. ¿Por qué no decir alto lo que todos dicen en voz baja? Los demás puntos del tratado se reducirían a pocas condiciones para hacerlo más llevadero. Dieciséis meses después me tocó la suerte de ser el primero, el único que inicié la paz resueltamente. No se me ha oído y se me ha correspondido con una crucifixión. En cambio, jlos contrarios a mi idea han crucificado a la Patria!! (Carta de Luis M. Duarte al Ministro Plenipotenciario de Chile en el Perú, Jovino Novoa. Lima, 03 de noviembre de 1882. En Ahumada, 1898, VII, p. 382).

A diferencia de Iglesias, Duarte no poseía unos sólidos contactos políticos que le permitieran hacer viable un proyecto propio. Enemistado con Piérola «por no tener espíritu cortesano» y nauseado del civilismo, se une a Castro Zaldívar en la lucha por imponer una nueva actitud de los terratenientes, que tienen ahora la posibilidad y oportunidad de hacer diferente la historia, directamente y con sus propias manos. Iglesias contó con el apoyo velado, primero, y sin tapujos después de los nacionales pierolistas, que, ante la invitación hecha por Julio Hernández, principal asesor iglesista, no trepidaron en abandonar las ideas primigenias de su líder, que aún permanecía en Europa. 
Iglesias, Castro Zaldívar, Duarte y Hernández fueron actores sociales que se encontraban articulados por su acendrado anticivilismo y por ser proclives inicialmente al pierolismo, tratando de forjar una nueva identidad con una propuesta no tan innovadora: la regeneración nacional.

\section{Relación de la Asamblea con el Gobierno Regenerador de la República}

En este cónclave regional el día 25 de diciembre de 1882, Iglesias, saliente jefe superior del norte (abril - diciembre 1882), se presentó e hizo su balance explicando, como político y terrateniente, la forma de llevar adelante las gestiones de paz. Al igual que García Calderón, Montero y Piérola opinaba que era imposible continuar la guerra contra Chile.

Mientras tuvimos naves, mientras tuvimos ejércitos, armas, recursos, esperanzas, la guerra, obstinada pudo disculparse. Más, cuando todo, absolutamente todo, se ha agotado o perdido, mantener el estado de guerra es un crimen... Mientras más se prolongue la mortal dolencia, más se alejan las esperanzas de salvación para nuestra nacionalidad agonizante. La guerra desde febrero de 1880, no se hace a Chile, sino a nuestros propios desventurados pueblos (Congreso de la República, 1882).

Para Iglesias el reloj indefectiblemente marcaba la hora de finalizar este conflicto que amenazaba no sólo sus haciendas sino su misma condición de terrateniente, al observar a los campesinos alzados en armas que luchaban contra los chilenos y que más tarde no dudarían en atacar a los hacendados colaboracionistas. Además, resultó que la devastación del circuito regional del norte era desesperante para una posible reconstrucción. En su opinión, era prioritario recomponernos de las secuelas de la guerra y renovar el escenario político, alejando a quienes tantos daños causaron muchísimos estragos para el Perú.

A partir de esta exposición de ideas, Iglesias sostendrá hasta el fin de su gobierno, en 1885, la idea de la regeneración como uno de los principios, es decir, un nuevo inicio, una refundación de la República que lo tenía a él como el líder que encabezaría una serie de procesos y reformas que se encontraban postergadas por responsabilidad de los partidos políticos.

Iglesias asumía contar con una representatividad nacional y actúo en nombre de todos los pueblos esquilmados por la guerra, haciendo suya la crítica a la conjunción de partidos (civilista y pierolista) y a su lucha por el poder, cegados por mezquindades no veían que la paz y un cese unilateral de hostilidades que se encontraba en sus manos. Iglesias movilizó sus intereses terratenientes y las proyectó como si fuera una necesidad nacional:

El pueblo ha dado su sangre, sus ahorros, su pan del día, conforme se lo han exigido, con promesas delirantes de triunfo o de reparación, los que han arbitrado de su suerte. Nada más tiene que dar. Desengañado, en cuanto al éxito de una guerra que la han fomentado y siguen fomentándola ambiciosos sin corazón y miserables intrigantes; de una guerra que sólo le ha traído ruina y vergüenzas, el pueblo peruano quiere la paz. Extenuado y a merced de los que aún conservan armas que no supieron manejar en el momento oportuno contra el enemigo común, y sí descargarlas contra sus indefensos compatriotas; descreído por que a cada momento sufre nuevas decepciones y se le envuelve en nuevas farsas mal urdidas por merodeadores políticos, ve en la paz inmediata su única salvación posible (Congreso de la República, 1882).

En el primer semestre de 1883 Iglesias regía como presidente de la República solamente en Cajamarca. No cuenta con recursos económicos para administrar y es dependiente de la voluntad 
chilena que consiente su conformación. Por su parte, la Asamblea del Norte depende logística y económicamente de los recursos que le provee Iglesias.

Luego de ser ungido como presidente de la República, Iglesias vio en su actitud cierta condición mesiánica: él era el hombre indicado por la Providencia para sacar al Perú de la caótica situación en la que se encontraba atrapado.

En momentos supremos y decisivos cuando se trata de resolver sobre la vida o la muerte de la república, una gran porción del pueblo peruano me ha impuesto, por medio de sus representantes, la aceptación del título con que a vosotros me dirijo. Comprendo que atravieso por la época más difícil de mi vida, como peruano y como hombre de honor. Tal es la magnitud y tales las trascendencias de la obra que emprendo sin vacilar. Se me ha creído necesario al frente de una revolución salvadora que devuelva al Perú la paz externa e interna y con la paz la fe en sus grandes destinos. He querido eximirme de tarea tan gloriosa, por creerla superior a mis fuerzas, pero toda vez que el sacrificio se me exige, el corazón me impulsa a obedecer (Proclama del Presidente Regenerador Miguel Iglesias. Cajamarca, 15 de enero de 1833. En Ahumada, 1898, VII, p. 468).

La interacción entre el nuevo gobierno y los legisladores norteños era permanente. En una oportunidad, la Asamblea solicitó al Ejecutivo informes por el abandono de los puestos encomendados inicialmente a José Mercedes Puga, Juan de Dios Torres Lara y Jacinto Dávila (Iglesias, 1883, s/f). Por su parte, Cruz Novoa, asambleísta por Hualgayoc, solicitó informes sobre la situación bélica al Oficial Mayor de Relaciones Exteriores y también parlamentario Julio Hernández (Iglesias, 1883, s/f). Este representante realizó interpelaciones al ministro general Lorenzo Iglesias en la Asamblea, el 15 marzo de 1883 (Iglesias, 1883, s/f). Pero no fue el único. El representante por Lambayeque, Santiago Vásquez, también interpelaría al hermano del presidente y al parecer por la crispación de la arena política no terminó bien la jornada porque se asentó una queja contra el mismo funcionario, quien en su descargo sostuvo:

Me es altamente satisfactorio declarar desde ahora que jamás tuve en cuenta inferir ofensa alguna al h diputado Sr. Vásquez, ni como representante porque reconozco los fueros de ese alto cargo, ni siquiera como amigo particular a quien profeso sincera estimación. Menos todavía podría permitir que esa supuesta ofensa alcanzara a la soberana asamblea, cuya armonía y respetabilidad entran en mis convicciones, en materia de gobierno como elemento único para el buen desempeño de las funciones que me están encomendadas y de cuyo apoyo jamás me separarán (Iglesias, 1883, s/f).

La dependencia de la Asamblea con Iglesias fue notable. El cónclave regional no tenía ni para cancelar sus propios útiles de escritorio, lo que el gobierno tuvo que impartir órdenes para que la Caja Fiscal de Cajamarca abone a la Asamblea los nueve soles 84 centavos plata para cancelar las dos cuentas por ese concepto (Iglesias, 1883, s/f). Lo mismo ocurrió para la remisión de la correspondencia oficial entre Lima y Cajamarca, por lo que el ministro general dispuso la entrega de 38 soles y 47 centavos plata por los servicios de transporte y los gastos hechos por Adolfo Ebell en esta actividad (Iglesias, 1883, s/f).

Allí no acababa todo, el costo por pago de dietas, traslado a Cajamarca, gastos de instalación y las mesadas a los diputados del norte también eran abonados por el gobierno de Iglesias, tal como se puede apreciar en el anexo del presente artículo. 
A pesar de esto, la carestía casi absoluta de recursos era la principal característica del naciente gobierno de Iglesias, quien, para conmemorar la debelación del alzamiento en Chota de 1882 por orden de la Asamblea del Norte, apuntará:

Deberes de todo género que el gobierno reconoce, le imponen la obligación de honrar la memoria de los esforzados patriotas que sacrifican su existencia en defensa del orden y de las instituciones, y si no lo ha cumplido hasta hoy respecto de las víctimas en el encuentro de Lara - Chota, y a pesar de haber recibido aún la resolución de la soberana asamblea fecha 29 de enero último, es porque las circunstancias del erario cuya estrechez se acrecienta cada día de un modo notorio, no se lo permiten todavía no obstante de todo su anhelo y esfuerzos. Reservando pues para la oportunidad más inmediata el cumplimiento de su deber y de lo que ha dispuesto la honorable Asamblea sobre los honores fúnebres de las víctimas de Lara Chota (Iglesias, 1883, s/f).

\section{Relación de la Asamblea con la opinión pública y la decisión de respaldo chileno}

La Asamblea del Norte envió sus respectivos mensajes a la nación al iniciar y cerrar sus sesiones. Asimismo, en el Pleno de la Asamblea se procedió a dar lectura del mensaje del nuevo presidente de la República, Miguel Iglesias, como respuesta crítica al sistema de partidos tradicionales (civilismo, pradismo y pierolismo). Propuso la reconstrucción nacional recogiendo el ideal pierolista de la regeneración y negociar la paz con Chile. Se intentó desmarcar del pierolismo, pero al no contar con los suficientes cuadros políticos idóneos, desarrollarán una simbiosis apoyándose mutuamente, escindiendo en dos al pierolismo por su expectativa de retomar el poder.

En su primer manifiesto, el 29 de diciembre de 1883, la Asamblea da a conocer su posición frente a la guerra. Resaltó el supuesto abandono de la región norte en manos de la incertidumbre y de las fuerzas chilenas. Critica a Montero por seguir una política errática y desprovista de definiciones en torno a la paz, lo que dejaba abierta la posibilidad para buscar replanteamientos, siendo la idea de la regeneración, un tema fundamental para la reconstrucción del Perú:

Tampoco fue más afortunado el contralmirante Montero, que le sucedió en el mando con carácter de vicepresidente, porque es público y notorio a los departamentos del norte, que este mandatario adoptó y siguió observando cierta política dudosa que no era paz ni era guerra, revelando más bien una conducta meramente expectativa, y dejando a estos pueblos en una situación indefinida, y sumidos en la más completa anomalía respecto a su porvenir político, se ausentó hacia la parte sur, quedando el norte aislado y entregado a su propia suerte (Manifiesto de la Soberana Asamblea del Norte a los demás pueblos de la República Peruana. Cajamarca, 29 de diciembre de 1882. En Ahumada, 1898, VII, p. 406).

En esa línea y sin equívoco alguno, el cuerpo legislativo del norte mostró todas sus cartas al señalar cuáles fueron realmente los móviles que obligaron a sus miembros a reunirse. Básicamente, dos razones: cesar la guerra y designar a un gobierno dispuesto a escuchar frontalmente los pedidos chilenos. Esa es la conclusión del documento emitido el 28 de abril de 1883, cuando dirige su segundo pronunciamiento a los pueblos de la República:

Dos fueron los fines de nuestra convocatoria; resolver lo más conveniente en el sentido de la guerra o la paz con Chile, y en el último caso la creación de un gobierno que la emprendiera sin vacilar. En cuanto a lo primero, la asamblea comprendiendo la importancia de la paz, no solo como bien presente, sino como esperanza para el porvenir, ha dado una ley en este 
sentido y pronto muy pronto el país podrá ver el resultado de esos trabajos. En cuanto a lo segundo, hemos creado un gobierno fuerte, honrado y circunspecto y dándole las facilidades necesarias para el objeto de su creación (Manifiesto de la Soberana Asamblea del Norte a los demás pueblos de la República Peruana. Cajamarca, 28 de abril de 1883. En Ahumada, VII, p. 468).

En esos momentos, Iglesias sólo tenía el control parcial de Cajamarca, ya que algunas provincias de la región estaban en manos de otros caudillos como Becerra o Puga su comportamiento fue calificado como cisma por García Calderón, traición por Montero y Candamo, y oportunidad propicia por los pierolistas: Iglesias salía al ruedo político confinado entre los andes del norte, con un título formal de mandatario supremo, pero sin el reconocimiento diplomático y menos del contendor chileno. Tachado por Arequipa, Iglesias se encontraba aislado totalmente, dependiendo exclusivamente a la paciencia, tenacidad y resignación que ofreciera a las cláusulas de paz que Chile impondría.

Por ello, los civilistas no le daban la importancia a los regeneradores. Se bufaban de Iglesias. Manuel Candamo era implacable y se ratificaba en la incredulidad de creer que los chilenos tratarían con él:

Mucho mal ha hecho al país ese imbécil, pues si no hubiera sido por su traición hace tiempo que la paz estaría hecha y se habrían evitado muchas desgracias y males de todo género. Ya ése no tiene remedio y lo necesario es concluir con ese grupo funesto, como grupo político, y que el señor Iglesias vuelva a criar vacas que es tal vez lo único para que podrá servir y de donde no debió salir jamás. (Carta de Manuel Candamo a Teresa Álvarez Calderón. $N^{\circ}$ 125. Chillán, 20 de mayo de 1883. En José de la Puente Candamo, 2008, p. 344).

Iba delineándose la confrontación directa entre Arequipa y Cajamarca. Regeneradores y civilistas tomaban posiciones para el crudo enfrentamiento que se desencadenaría en 1883. Chile apostaría nuevamente por un nuevo gobierno a su sombra, pero esta vez tendría el cuidado y el tino para monitorear todas sus actividades y no se generasen situaciones embarazosas como la que creó García Calderón. 1883 sería un año crucial para Iglesias y fatal para Montero. Para este último, su crédito político se devaluó enormemente por su inacción, de tal forma que ni los mismos civilistas tenían confianza en su gobierno.

De otro lado, el apoyo del pierolismo no ocurrió tan rápido como inicialmente se pensó. Para comprender las ideas del gobierno de Iglesias, revisaremos las opiniones de Juan Martín Echenique, quien fue uno de los principales representantes de la Asamblea de Ayacucho en 1881 y jefe principal de la Reserva de Lima en la defensa de la capital el mismo año. Para 1883, Echenique era partidario de la fusión de partidos, una idea que requería precisiones pero que reflejaba la idea de conformar una junta de gobierno con personalidades de los principales partidos políticos de Lima y quiénes deberían llevar a través de la concertación un gobierno de unidad para resolver el tema de la paz.

En esa línea, Echenique envió una carta a Julio Hernández, quien descartó tajantemente la idea de la fusión de partidos y resaltó el esfuerzo que hacía la Asamblea de Cajamarca, en la cual él participaba como representante de Piura: 


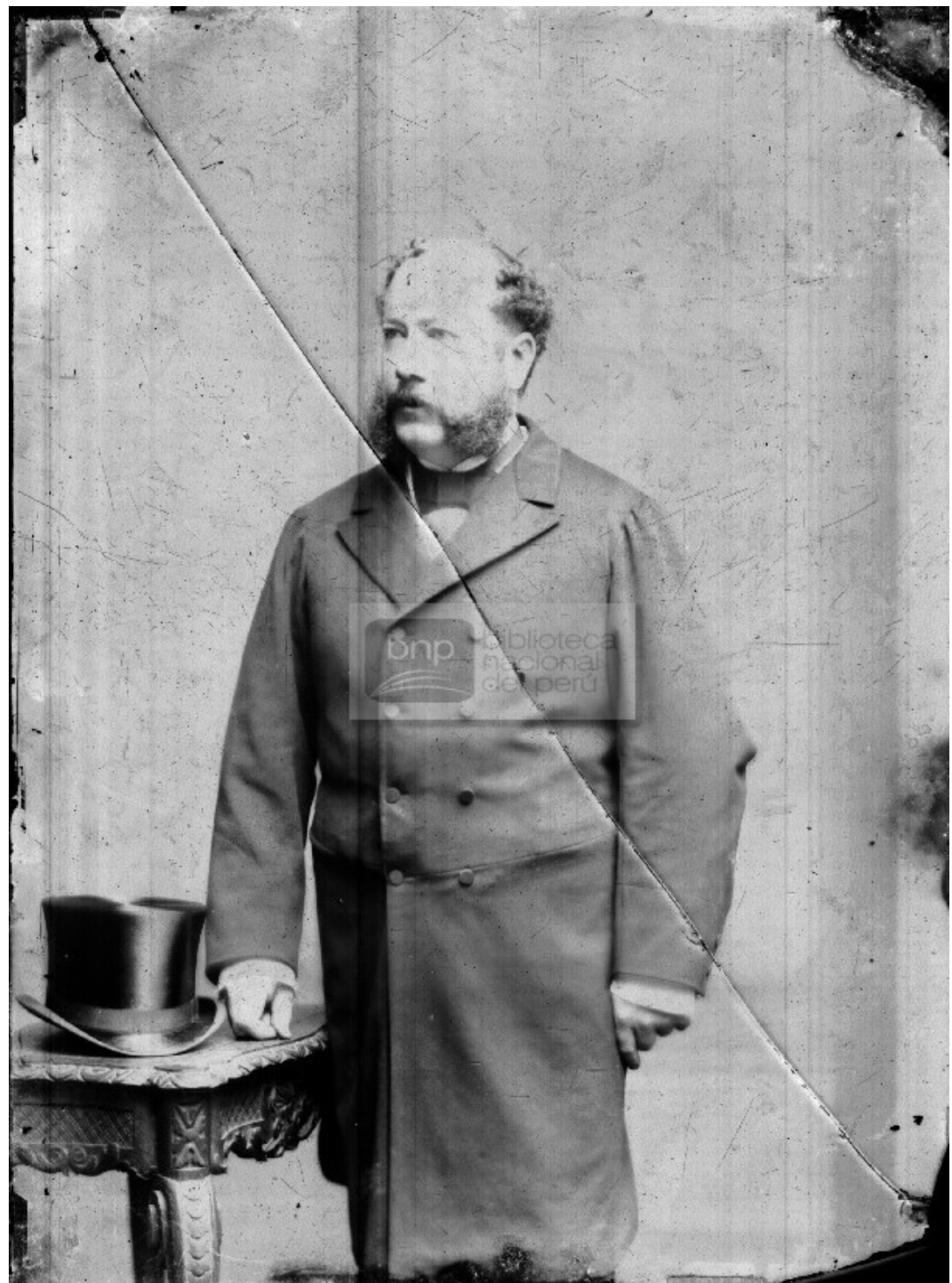

Fotografía N 02: Vidal García y García. Diputado por San Martín y presidente de la Asamblea del Norte. Fotografía tomada de la Colección Courret de la Biblioteca Nacional del Perú.

A despecho de todos los anatemas fulminados y de todos los resortes puestos en juego para malograr el movimiento político del norte, la Asamblea pudo reunirse, sin obstáculo, el 25 de diciembre próximo pasado, y en consecuencia de sus primeras deliberaciones dio la ley de paz y creó un gobierno nacional para tratarla. Jefe de ese gobierno fue unánimemente aclamado el general Iglesias (Carta de Julio Hernández a Juan Martín Echenique. Cajamarca, 07 de febrero de 1883. En Ahumada, 1898, VII, p. 477).

De esta forma, Iglesias se reafirmó en gobernar en solitario, sin compartir el poder con otro partido. Por su parte, el historiador chileno Bulnes cuestionó la aparición de Miguel Iglesias como una figura condicionada a la voluntad de Chile como un producto más de las intrigas de La Moneda:

Se ha dicho y creyó uniformemente en el Perú que Iglesias fue lanzado por Chile a la arena política; y que todos los pasos que diera en la memorable época que rememoro fueron sugestión suya. Estas afirmaciones son inexactas. Iglesias procedió por inspiración propia o por influencia de sus amigos políticos, los pierolistas, creyendo complacer a su jefe ausente, y cuando estos los abandonaron, perseveró en su plan solo y con igual energía 
que antes. El retiro de Piérola le da a su acción un relieve personal enorme. (Bulnes, 1919, III, p. 360, 367)

Sin embargo, debemos precisar que, si bien Chile no creó directamente a este gobierno, contribuyó enormemente a su sostenimiento y consolidación. Quizás haya influido la enorme decepción que le causó el régimen de García Calderón y cómo forjaron su emergencia: la labor de consulta a las autoridades chilenas de ocupación para el funcionamiento de un nuevo gobierno lo realizó la junta de notables en 1881 tiene similitud con la que desarrolló Mariano Castro en 1882 ante Jovino Novoa. El panorama para Chile era negativo por lo que se pensó seriamente en Iglesias a fines de 1882:

Tenía yo poca fe en lo que pudiera hacer García Calderón, a quien por otra parte no habrían prestado apoyo ni Montero ni Cáceres. El mismo Piérola me inspira también poca, no sé porque no la merezca el hombre o porque yo la vaya perdiendo. El único que diviso serio, atendidas sus declaraciones, es Iglesias. Al menos ha tenido el valor suficiente para reconocer la necesidad de llegar a la paz con cesión territorial (Carta de Jovino Novoa al presidente Santa María. Lima, 01 de noviembre de 1882. En Bulnes, 1919, III, p. 365).

Pero, el presidente Santa María sabía perfectamente que aún debían evaluar y observar el desempeño de Iglesias antes de respaldarlo, más aún si no contaba con el apoyo popular necesario ni los recursos para ampliar su influencia en los departamentos del centro y el sur (Carta de Jovino Novoa al presidente Santa María. Lima, 24 de enero de 1883. En: Bulnes, 1919, III, p. 390). Con el arribo de José Antonio de Lavalle y Avelino Aramburú como miembros de la misión peruana a cargo de negociar la paz, Santiago decidió ir hasta el final con Iglesias, con quien firmarían finalmente la tan ansiada paz con la entrega perpetua de Tarapacá:

Creo que estamos en la misma cuerda y por ahora no veo a que otra parte pudiéramos llevar nuestros esfuerzos. No queda más que Iglesias, digan lo que quieran contra él los de aquí y los de allá. Es el único hombre que tiene coraje para decir lo que siente y que lo tendrá para hacer lo que crea conveniente. Nosotros debemos fortificarlo y ver el modo que su poder sea absoluto y verdadero en todo el Norte. Si logramos darle cuerpo debemos apresurarnos a tratar con él, que, si mañana cae porque sus mismos paisanos lo tumban, no por eso dejará por cierto, verdadero y eficaz el tratado que habíamos firmado con él (Carta del presidente Santa María a Jovino Novoa. Santiago, 03 de febrero de 1883. En Bulnes, 1919, III, p. 390).

En esa línea, Santa María no solo coordinó con Jovino Novoa, sino también con Patricio Lynch para que proteja militarmente al gobierno iglesista del posible ataque que dirigiría Cáceres desde Junín hacia Cajamarca:

Persuadido como estoy que no habrá paz ni con Piérola ni con Calderón ni con ninguno de estos hombres que no tienen el valor para afrontar una situación y dominarla, te debes empeñar en reforzar a Iglesias, único hombre honrado que aparece, a fin de ponernos en condiciones de ajustar con él la paz. Todos nuestros esfuerzos deben en estos momentos dirigirse en este sentido (Carta del presidente Santa María a Patricio Lynch. Santiago, 09 de febrero de 1883. En Bulnes, 1919, III, p. 390).

Obviamente, Lynch pondría en marcha las órdenes presidenciales y resguardaría a Iglesias de la maniobra militar de Cáceres, quien partió para el norte por la presión de las tres expediciones chilenas enviadas para exterminarlo. Aunque también con este movimiento era posible aniquilar 
la insurgencia de Iglesias. Por esta razón, Lynch ordenó al coronel Gorostiaga para que evite la reunión entre Cáceres y Recabarren en Áncash:

Es obvio que Recabarren, sea unido a Cáceres o no pretende atacar al general Iglesias y quizás juzgue lograrlo mejor, esquivando el encuentro previo con nuestras fuerzas y para ello toma el camino a Cajamarca por Parcoy y Pataz. Sea lo anterior exacto o no, debe us conformar todos sus movientes, a fin de producir el doble resultado que te le tiene este Cuartel General encomendado a las fuerzas de su mando, es decir, destrozar a Recabarren y demás montoneros, estorbando se reúna con Cáceres y proteger al general Iglesias de este último caudillo (Instrucciones de Patricio Lynch al coronel Alejandro Gorostiaga. En Patricio Lynch, 1884, p. 291).

El corolario de este apoyo culminó con la victoria chilena en Huamachuco y la consolidación de Iglesias en el norte, firmando meses después el Tratado de Ancón, una paz hecha y diseñada a la figura que quería Chile.

Fotografía N03: José Antonio de Lavalle. Ministro de Relaciones Exteriores de la administración de Iglesias y gestor principal del Tratado de Ancón. Fotografía tomada de la Colección Courret de la Biblioteca Nacional del Perú. 


\section{Conclusiones}

En la segunda mitad del año 1882 se produjo la colisión de intereses entre el gobierno provisorio, encabezado por Lizardo Montero y otro que lo desafió en el norte al mando de Miguel Iglesias. Luego de la devastación chilena en Cajamarca, Iglesias dio a conocer sus propuestas en el Grito de Montán, pidiendo cesar de inmediato la guerra a través de la convocatoria a una Asamblea del Norte, circunscripción donde él se desempeñaba como jefe político militar. Este pedido representó los intereses de los terratenientes de la sierra norte por concluir una guerra que llevaba cuatro años y que amenazaba con expandirse por toda Cajamarca.

Terminar la guerra evitaría la destrucción de los circuitos económicos regionales del norte y el incremento de los desórdenes sociales que podía motivar el levantamiento de las comunidades campesinas como ocurría en el centro del país. Con el apoyo de su círculo familiar (Mariano Castro y Julio Hernández) se logró instalar la Asamblea que lo nombró Presidente Regenerador y lo habilitó para iniciar negociaciones con Chile, a espaldas del gobierno de Montero existente en Arequipa y a los denodados esfuerzos de las fuerzas de Cáceres. Su gobierno recién inaugurado contó con la simpatía inicial de los pierolistas. De forma personal, Lavalle se comprometió con la causa iglesista y se convirtió en su principal negociador de la paz que lo condujo a la suscripción del Tratado de Ancón en octubre de 1883.

La producción normativa de la Asamblea del Norte instauró un nuevo gobierno nacional, encabezado por el general Miguel Iglesias. Prácticamente esta fue su única misión como cuerpo legislativo, ya que el resto de leyes aprobadas tenían un alcance local (Cajamarca) y que no involucraba directamente a las demás regiones como Piura, La Libertad, Áncash, Loreto, Lambayeque y Amazonas. La aplicación real de la legislación aprobada no pudo verificarse porque el gobierno naciente no tuvo la fuerza ni el respaldo popular para trascender la ciudad de Cajamarca. Comparativamente frente a otros Congresos durante la guerra, la Asamblea del Norte estuvo en funciones desde fines de diciembre de 1882 hasta abril de 1883, siendo uno de los periodos más dilatados. Otro detalle que llama la atención es que tanto en la inauguración como clausura de sesiones envió sendos pronunciamientos a los pueblos del Perú sobre su postura frente a cómo arribar a la paz.

La decisión de apostar por la paz incondicional de Iglesias y la Asamblea del Norte fue el primer paso para llamar la atención de Chile, que se encontraba plenamente decepcionado de García Calderón por utilizar la intervención norteamericana en su favor. Una estrategia que le permitió ganar tiempo no definiendo el escenario de la paz frente a peruanos y bolivianos, el presidente Santa María accedió a liberar y colocar como plenipotenciarios de la parte peruana a José Antonio de Lavalle y su secretario Avelino Aramburú, quienes junto a Mariano Castro llevarían a cabo las conversaciones que tuvieron como resultado el protocolo de mayo de 1883, antecedente directo del tratado de Ancón. 


\section{ANEXO No 01}

Presupuesto que la comisión de policía presenta a la honorable asamblea en cumplimiento del artículo 110 del reglamento interior, con expresión de los emolumentos que corresponden a cada uno de los señores diputados, etc. Cajamarca, enero 31 de 1883.

Sala para Investigadores de Manuscritos y Libros Raros de la Biblioteca Nacional del Perú. Código de barras: 2000010738

\begin{tabular}{|c|c|c|c|c|c|}
\hline Diputado de la Asamblea del Norte & $\begin{array}{c}\text { Total, de leguas } \\
\text { con respecto a } \\
\text { Cajamarca, sede de la } \\
\text { Asamblea del Norte }\end{array}$ & $\begin{array}{l}\text { Pago por traslado } \\
\text { en leguas } \\
\text { recorridas }\left({ }^{*}\right)\end{array}$ & Mesada & Dieta & Total \\
\hline & Soles & Soles & Soles & Soles & Soles \\
\hline $\begin{array}{l}\text { Rafael Chavarri, diputado por Bongará hacia San } \\
\text { Carlos, capital de su provincia }\end{array}$ & 65 & 156 & & & \\
\hline $\begin{array}{l}\text { Por } 15 \text { días anteriores a las sesiones a } 10 \text { soles } \\
\text { diarios }\end{array}$ & & & 150 & & \\
\hline Por su mesada de establecimiento. & & & 300 & & 606 \\
\hline $\begin{array}{l}\text { Don Mariano Burga, diputado por Celendín hacia } \\
\text { la capital de su provincia }\end{array}$ & 12 & 28.8 & & & \\
\hline $\begin{array}{l}\text { Por } 15 \text { días anteriores y } 15 \text { posteriores a las } \\
\text { sesiones a } 10 \text { soles diarios. }\end{array}$ & & & 300 & & \\
\hline Por su mesada de establecimiento. & & & 300 & & \\
\hline $\begin{array}{l}\text { Por sus dietas en los } 38 \text { días calculados a } 10 \text { soles } \\
\text { diarios. }\end{array}$ & & & & 380 & 1008.8 \\
\hline $\begin{array}{l}\text { Coronel Vidal García y García, diputado por } \\
\text { Moyobamba }\end{array}$ & 102 & 244.8 & & & \\
\hline $\begin{array}{l}\text { Por } 15 \text { días anteriores y } 15 \text { posteriores a las } \\
\text { sesiones a } 10 \text { soles diarios. }\end{array}$ & & & 300 & & \\
\hline Por su mesada de establecimiento. & & & 300 & & \\
\hline $\begin{array}{l}\text { Por sus dietas en los } 38 \text { días calculados a } 10 \text { soles } \\
\text { diarios. }\end{array}$ & & & & 380 & 1308.8 \\
\hline $\begin{array}{l}\text { Presbítero José Luis Salazar, diputado por } \\
\text { Cajatambo, a la capital de su provincia }\end{array}$ & & 328.8 & & & \\
\hline $\begin{array}{l}\text { Por } 15 \text { días anteriores y } 15 \text { posteriores a las } \\
\text { sesiones a } 10 \text { soles diarios. }\end{array}$ & & & 300 & & \\
\hline Por su mesada de establecimiento. & & & 300 & & \\
\hline $\begin{array}{l}\text { Por sus dietas en los } 38 \text { días calculados a } 10 \text { soles } \\
\text { diarios. }\end{array}$ & & & & 380 & 1308.8 \\
\hline $\begin{array}{l}\text { Roberto Osores, diputado por Chota a la capital de } \\
\text { su provincia }\end{array}$ & 19 & 45.6 & & & \\
\hline $\begin{array}{l}\text { Por } 15 \text { días anteriores y } 15 \text { posteriores a las } \\
\text { sesiones a } 10 \text { soles diarios. }\end{array}$ & & & 300 & & \\
\hline Por su mesada de establecimiento. & & & 300 & & \\
\hline $\begin{array}{l}\text { Por sus dietas en los } 38 \text { días calculados a } 10 \text { soles } \\
\text { diarios. }\end{array}$ & & & & 380 & 1025.6 \\
\hline Manuel Francisco Burga, diputado por Cajamarca. & 0 & 0 & & & \\
\hline $\begin{array}{l}\text { Por } 15 \text { días anteriores y } 15 \text { posteriores a las } \\
\text { sesiones a } 10 \text { soles diarios. }\end{array}$ & & & 300 & & \\
\hline Por su mesada de establecimiento. & & & 300 & & \\
\hline $\begin{array}{l}\text { Por sus dietas en los } 38 \text { días calculados a } 10 \text { soles } \\
\text { diarios. }\end{array}$ & & & & 380 & 980 \\
\hline $\begin{array}{l}\text { Coronel Lorenzo Iglesias, diputado por Huari a la } \\
\text { capital de su provincia }\end{array}$ & 132 & 316.8 & & & \\
\hline $\begin{array}{l}\text { Por } 15 \text { días anteriores a las sesiones a } 10 \text { soles } \\
\text { diarios. }\end{array}$ & & & 150 & & \\
\hline Por su mesada de establecimiento. & & & 300 & & \\
\hline
\end{tabular}


Abanto

\begin{tabular}{|c|c|c|c|c|c|}
\hline \multirow[t]{2}{*}{ Diputado de la Asamblea del Norte } & $\begin{array}{c}\text { Total, de leguas } \\
\text { con respecto a } \\
\text { Cajamarca, sede de la } \\
\text { Asamblea del Norte } \\
\end{array}$ & $\begin{array}{l}\text { Pago por traslado } \\
\text { en leguas } \\
\text { recorridas }(*)\end{array}$ & Mesada & Dieta & Total \\
\hline & Soles & Soles & Soles & Soles & Soles \\
\hline $\begin{array}{l}\text { Por } 16 \text { días hasta el } 9 \text { del presente sus dietas a } 10 \\
\text { soles diarios. }\end{array}$ & & & & 160 & 926.8 \\
\hline $\begin{array}{l}\text { Coronel Pedro Urrunaga, diputado por San Martín, } \\
\text { a Tarapoto, la capital de su provincia }\end{array}$ & 38 & 319.2 & & & \\
\hline $\begin{array}{l}\text { Por } 15 \text { días anteriores y } 15 \text { posteriores a las } \\
\text { sesiones a } 10 \text { soles diarios. }\end{array}$ & & & 300 & & \\
\hline Por su mesada de establecimiento. & & & 300 & & \\
\hline $\begin{array}{l}\text { Por sus dietas en los } 38 \text { días calculados a } 10 \text { soles } \\
\text { diarios. }\end{array}$ & & & & 160 & 1299.2 \\
\hline $\begin{array}{l}\text { Don Mariano Castro Zaldívar, diputado por } \\
\text { Cajamarca }\end{array}$ & 0 & & & & \\
\hline $\begin{array}{l}\text { Por } 15 \text { días anteriores a las sesiones a } 10 \text { soles } \\
\text { diarios. }\end{array}$ & & & 150 & & \\
\hline Por su mesada de establecimiento. & & & 300 & & \\
\hline $\begin{array}{l}\text { Por sus dietas de } 10 \text { días hasta el } 4 \text { del presente a } \\
10 \text { soles diarios. }\end{array}$ & & & & 100 & 550 \\
\hline \multicolumn{6}{|l|}{$\begin{array}{l}\text { A partir de esta fecha la comisión ha creído } \\
\text { conveniente no designarle dietas por el tiempo de } \\
\text { su licencia. }\end{array}$} \\
\hline $\begin{array}{l}\text { Coronel Adolfo Salmón, diputado por el Bajo } \\
\text { Amazonas, a lquitos, capital de su provincia }\end{array}$ & 230 & 552 & & $\begin{array}{l}\text { Suma a la } \\
\text { vuelta }\end{array}$ & 8908 \\
\hline $\begin{array}{l}\text { Por } 15 \text { días anteriores y } 15 \text { posteriores a las } \\
\text { sesiones a } 10 \text { soles diarios. }\end{array}$ & & & 300 & & \\
\hline Por su mesada de establecimiento. & & & 300 & & \\
\hline $\begin{array}{l}\text { Por sus dietas en los } 38 \text { días calculados a } 10 \text { soles } \\
\text { diarios. }\end{array}$ & & & & 380 & 1532 \\
\hline $\begin{array}{l}\text { Don Segundo Bringas, diputado por la provincia de } \\
\text { Luya, a la capital de su provincia }\end{array}$ & 58 & 139.2 & & & \\
\hline $\begin{array}{l}\text { Por } 15 \text { días anteriores a las sesiones a } 10 \text { soles } \\
\text { diarios. }\end{array}$ & & & 150 & & \\
\hline Por su mesada de establecimiento. & & & 300 & & \\
\hline $\begin{array}{l}\text { Por sus dietas de } 16 \text { días hasta el } 9 \text { del presente a } \\
10 \text { soles diarios. }\end{array}$ & & & & 160 & 749.2 \\
\hline $\begin{array}{l}\text { Coronel Manuel Ezequiel del Campo, diputado por } \\
\text { la provincia del Huallaga, a Saposoa, a la capital de } \\
\text { la provincia, }\end{array}$ & 133 & 319.2 & & & \\
\hline $\begin{array}{l}\text { Por } 15 \text { días anteriores y } 15 \text { posteriores a las } \\
\text { sesiones a } 10 \text { soles diarios. }\end{array}$ & & & 300 & & \\
\hline Por su mesada de establecimiento. & & & 300 & & \\
\hline $\begin{array}{l}\text { Por sus dietas en los } 38 \text { días calculados a } 10 \text { soles } \\
\text { diarios. }\end{array}$ & & & & 380 & 1299.2 \\
\hline $\begin{array}{l}\text { Don Julián Rojas, diputado por Otuzco, a la capital } \\
\text { de su provincia }\end{array}$ & 44 & 105.6 & & & \\
\hline $\begin{array}{l}\text { Por } 15 \text { días anteriores y } 15 \text { posteriores a las } \\
\text { sesiones a } 10 \text { soles diarios. }\end{array}$ & & & 300 & & \\
\hline Por su mesada de establecimiento. & & & 300 & & \\
\hline $\begin{array}{l}\text { Por sus dietas en los } 38 \text { días calculados a } 10 \text { soles } \\
\text { diarios. }\end{array}$ & & & & 380 & 1085.6 \\
\hline $\begin{array}{l}\text { Don Santiago Rodríguez, diputado por el cercado } \\
\text { de Chachapoyas, a la capital de su provincia }\end{array}$ & 53 & 127.2 & & & \\
\hline $\begin{array}{l}\text { Por } 15 \text { días anteriores y } 15 \text { posteriores a las } \\
\text { sesiones a } 10 \text { soles diarios. }\end{array}$ & & & 300 & & \\
\hline Por su mesada de establecimiento. & & & 300 & & \\
\hline $\begin{array}{l}\text { Por sus dietas en los } 38 \text { días calculados a } 10 \text { soles } \\
\text { diarios. }\end{array}$ & & & & 380 & 1107.2 \\
\hline
\end{tabular}


Historia parlamentaria en la Guerra con Chile: la Asamblea de Cajamarca y el presidente regenerador Miguel Iglesias (1882 - 1883)

\begin{tabular}{|c|c|c|c|c|c|}
\hline \multirow[t]{2}{*}{ Diputado de la Asamblea del Norte } & $\begin{array}{c}\text { Total, de leguas } \\
\text { con respecto a } \\
\text { Cajamarca, sede de la } \\
\text { Asamblea del Norte }\end{array}$ & $\begin{array}{l}\text { Pago por traslado } \\
\text { en leguas } \\
\text { recorridas }(*)\end{array}$ & Mesada & Dieta & Total \\
\hline & Soles & Soles & Soles & Soles & Soles \\
\hline $\begin{array}{l}\text { Don Juan M Tirado, diputado por el Alto } \\
\text { Amazonas, a Barba puerto, capital de la provincia }\end{array}$ & 131 & 314.4 & & & \\
\hline $\begin{array}{l}\text { Por } 15 \text { días anteriores y } 15 \text { posteriores a las } \\
\text { sesiones a } 10 \text { soles diarios. }\end{array}$ & & & 300 & & \\
\hline Por su mesada de establecimiento. & & & 300 & & \\
\hline $\begin{array}{l}\text { Por sus dietas en los } 38 \text { días calculados a } 10 \text { soles } \\
\text { diarios. }\end{array}$ & & & & 380 & 1294.4 \\
\hline $\begin{array}{l}\text { Presbítero Cruz Novoa, diputado por Hualgayoc, a } \\
\text { la capital de su provincia }\end{array}$ & 74 & 133.6 & & & \\
\hline $\begin{array}{l}\text { Por } 15 \text { días anteriores y } 15 \text { posteriores a las } \\
\text { sesiones a } 10 \text { soles diarios. }\end{array}$ & & & 300 & & \\
\hline Por su mesada de establecimiento. & & & 300 & & \\
\hline $\begin{array}{l}\text { Por sus dietas en los } 38 \text { días calculados a } 10 \text { soles } \\
\text { diarios. }\end{array}$ & & & & 380 & 1205.6 \\
\hline $\begin{array}{l}\text { Don Manuel Julio de la Rivera, diputado por } \\
\text { Pomabamba a la capital de su provincia }\end{array}$ & 149 & 357.6 & & & \\
\hline $\begin{array}{l}\text { Por } 15 \text { días anteriores y } 15 \text { posteriores a las } \\
\text { sesiones a } 10 \text { soles diarios. }\end{array}$ & & & 300 & & \\
\hline Por su mesada de establecimiento. & & & 300 & & \\
\hline $\begin{array}{l}\text { Por sus dietas en los } 38 \text { días calculados a } 10 \text { soles } \\
\text { diarios. }\end{array}$ & & & & 380 & 1337.6 \\
\hline $\begin{array}{l}\text { Dr. Don José A. Urteaga, diputado por Santa, a } \\
\text { Casma a la capital de su provincia }\end{array}$ & 125 & 300 & & & \\
\hline $\begin{array}{l}\text { Por } 15 \text { días anteriores y } 15 \text { posteriores a las } \\
\text { sesiones a } 10 \text { soles diarios. }\end{array}$ & & & 300 & & \\
\hline Por su mesada de establecimiento. & & & 300 & & \\
\hline $\begin{array}{l}\text { Por sus dietas en los } 38 \text { días calculados a } 10 \text { soles } \\
\text { diarios. }\end{array}$ & & & & 380 & 1280 \\
\hline $\begin{array}{l}\text { Cura Daciteo U. Mancuena, diputado por Huaylas, } \\
\text { a la capital de su provincia }\end{array}$ & 123 & 295.2 & & & \\
\hline $\begin{array}{l}\text { Por } 15 \text { días anteriores y } 15 \text { posteriores a las } \\
\text { sesiones a } 10 \text { soles diarios. }\end{array}$ & & & 300 & & \\
\hline Por su mesada de establecimiento. & & & 300 & & \\
\hline $\begin{array}{l}\text { Por sus dietas en los } 38 \text { días calculados a } 10 \text { soles } \\
\text { diarios. }\end{array}$ & & & & 380 & 1275 \\
\hline $\begin{array}{l}\text { Don Gerónimo Zevallos, diputado por Jaén, a la } \\
\text { capital de su provincia }\end{array}$ & 53 & 127.2 & & & \\
\hline $\begin{array}{l}\text { Por } 15 \text { días anteriores y } 15 \text { posteriores a las } \\
\text { sesiones a } 10 \text { soles diarios. }\end{array}$ & & & 300 & & \\
\hline Por su mesada de establecimiento. & & & 300 & & \\
\hline $\begin{array}{l}\text { Por sus dietas en los } 38 \text { días calculados a } 10 \text { soles } \\
\text { diarios. }\end{array}$ & & & & 380 & 1107 \\
\hline $\begin{array}{l}\text { Don Carlos G. Chocano, diputado por } \\
\text { Chachapoyas, a la capital de su provincia }\end{array}$ & 53 & 127.2 & & & \\
\hline $\begin{array}{l}\text { Por } 15 \text { días anteriores y } 15 \text { posteriores a las } \\
\text { sesiones a } 10 \text { soles diarios. }\end{array}$ & & & 300 & & \\
\hline Por su mesada de establecimiento. & & & 300 & & \\
\hline $\begin{array}{l}\text { Por sus dietas en los } 38 \text { días calculados a } 10 \text { soles } \\
\text { diarios. }\end{array}$ & & & & 380 & 1107 \\
\hline $\begin{array}{l}\text { Don Gabriel Muñoz, diputado por Pacasmayo, a } \\
\text { San Pedro, a la capital de su provincia }\end{array}$ & 28 & 67.2 & & & \\
\hline $\begin{array}{l}\text { Por } 15 \text { días anteriores y } 15 \text { posteriores a las } \\
\text { sesiones a } 10 \text { soles diarios. }\end{array}$ & & & 300 & & \\
\hline Por su mesada de establecimiento. & & & 300 & & \\
\hline
\end{tabular}


Abanto

\begin{tabular}{|c|c|c|c|c|c|}
\hline \multirow[t]{2}{*}{ Diputado de la Asamblea del Norte } & $\begin{array}{c}\text { Total, de leguas } \\
\text { con respecto a } \\
\text { Cajamarca, sede de la } \\
\text { Asamblea del Norte } \\
\end{array}$ & $\begin{array}{l}\text { Pago por traslado } \\
\text { en leguas } \\
\text { recorridas }(*)\end{array}$ & Mesada & Dieta & Total \\
\hline & Soles & Soles & Soles & Soles & Soles \\
\hline $\begin{array}{l}\text { Por sus dietas en los } 38 \text { días calculados a } 10 \text { soles } \\
\text { diarios. }\end{array}$ & & & & 380 & 367.2 \\
\hline $\begin{array}{l}\text { Dr. Don Francisco E Pesada, diputado por Pataz, a } \\
\text { Parcay, a la capital de su provincia }\end{array}$ & 52 & 125.8 & & & \\
\hline $\begin{array}{l}\text { Por } 15 \text { días anteriores y } 15 \text { posteriores a las } \\
\text { sesiones a } 10 \text { soles diarios. }\end{array}$ & & & 300 & & \\
\hline Por su mesada de establecimiento. & & & 300 & & \\
\hline $\begin{array}{l}\text { Por sus dietas en los } 38 \text { días calculados a } 10 \text { soles } \\
\text { diarios. }\end{array}$ & & & & 380 & 1005.8 \\
\hline $\begin{array}{l}\text { Don Juan B Cacho, diputado por Moyobamba, a la } \\
\text { capital de su provincia }\end{array}$ & 102 & 244.8 & & & \\
\hline $\begin{array}{l}\text { Por } 15 \text { días anteriores y } 15 \text { posteriores a las } \\
\text { sesiones a } 10 \text { soles diarios. }\end{array}$ & & & 300 & & \\
\hline Por su mesada de establecimiento. & & & 300 & & \\
\hline $\begin{array}{l}\text { Por sus dietas en los } 38 \text { días calculados a } 10 \text { soles } \\
\text { diarios. }\end{array}$ & & & & 380 & 1224.8 \\
\hline $\begin{array}{l}\text { Don Clemente Arana, diputado por Pallasca, a } \\
\text { Corongo, a la capital de su provincia }\end{array}$ & 67 & 160.8 & & & \\
\hline $\begin{array}{l}\text { Por } 15 \text { días anteriores y } 15 \text { posteriores a las } \\
\text { sesiones a } 10 \text { soles diarios. }\end{array}$ & & & 300 & & \\
\hline Por su mesada de establecimiento. & & & 300 & & \\
\hline $\begin{array}{l}\text { Por sus dietas en los } 38 \text { días calculados a } 10 \text { soles } \\
\text { diarios. }\end{array}$ & & & & 380 & 1140.8 \\
\hline $\begin{array}{l}\text { Don Antonio Espinoza, diputado por } \\
\text { Huancabamba, a la capital de su provincia }\end{array}$ & & 276 & & & \\
\hline $\begin{array}{l}\text { Por } 15 \text { días anteriores y } 15 \text { posteriores a las } \\
\text { sesiones a } 10 \text { soles diarios. }\end{array}$ & & & 300 & & \\
\hline Por su mesada de establecimiento. & & & 300 & & \\
\hline $\begin{array}{l}\text { Por sus dietas en los } 38 \text { días calculados a } 10 \text { soles } \\
\text { diarios. }\end{array}$ & & & & 380 & 1256 \\
\hline $\begin{array}{l}\text { Coronel Pablo Santillán, diputado por el cercado } \\
\text { de Huaraz, a la capital de su provincia }\end{array}$ & 105 & 292 & & & \\
\hline $\begin{array}{l}\text { Por } 15 \text { días anteriores y } 15 \text { posteriores a las } \\
\text { sesiones a } 10 \text { soles diarios. }\end{array}$ & & & 300 & & \\
\hline Por su mesada de establecimiento. & & & 300 & & \\
\hline $\begin{array}{l}\text { Por sus dietas en los } 38 \text { días calculados a } 10 \text { soles } \\
\text { diarios. }\end{array}$ & & & & 380 & 1272 \\
\hline $\begin{array}{l}\text { Coronel José Silva Santistevan, diputado por } \\
\text { Huaraz, a la capital de su provincia }\end{array}$ & 105 & 252 & & & \\
\hline $\begin{array}{l}\text { Por } 15 \text { días anteriores y } 15 \text { posteriores a las } \\
\text { sesiones a } 10 \text { soles diarios. }\end{array}$ & & & 300 & & \\
\hline Por su mesada de establecimiento. & & & 300 & & \\
\hline $\begin{array}{l}\text { Por sus dietas en los } 38 \text { días calculados a } 10 \text { soles } \\
\text { diarios. }\end{array}$ & & & & 380 & 1232 \\
\hline $\begin{array}{l}\text { Don José Ceijas diputado por Huamachuco, a la } \\
\text { capital de su provincia }\end{array}$ & 26 & 62.4 & & & \\
\hline $\begin{array}{l}\text { Por } 15 \text { días anteriores y } 15 \text { posteriores a las } \\
\text { sesiones a } 10 \text { soles diarios. }\end{array}$ & & & 300 & & \\
\hline Por su mesada de establecimiento. & & & 300 & & \\
\hline $\begin{array}{l}\text { Por sus dietas en los } 38 \text { días calculados a } 10 \text { soles } \\
\text { diarios. }\end{array}$ & & & & 380 & 1042 \\
\hline $\begin{array}{l}\text { Don José Santos Aduvire, diputado por Bongará, a } \\
\text { San Carlos, capital de su provincia }\end{array}$ & 65 & 156 & & & \\
\hline
\end{tabular}


Historia parlamentaria en la Guerra con Chile: la Asamblea de Cajamarca y el presidente regenerador Miguel Iglesias (1882 - 1883)

\begin{tabular}{|c|c|c|c|c|c|}
\hline Diputado de la Asamblea del Norte & $\begin{array}{l}\text { Total, de leguas } \\
\text { con respecto a } \\
\text { Cajamarca, sede de la } \\
\text { Asamblea del Norte }\end{array}$ & $\begin{array}{l}\text { Pago por traslado } \\
\text { en leguas } \\
\text { recorridas }\left({ }^{*}\right)\end{array}$ & Mesada & Dieta & Total \\
\hline & Soles & Soles & Soles & Soles & Soles \\
\hline $\begin{array}{l}\text { Por } 15 \text { días anteriores y } 15 \text { posteriores a las } \\
\text { sesiones a } 10 \text { soles diarios. }\end{array}$ & & & 300 & & \\
\hline Por su mesada de establecimiento. & & & 300 & & \\
\hline $\begin{array}{l}\text { Por sus dietas de } 11 \text { días hasta el } 4 \text { del presente } \\
\text { calculados a } 10 \text { soles diarios. }\end{array}$ & & & & 110 & 566 \\
\hline $\begin{array}{l}\text { Coronel Julio Hernández, diputado por Piura, a la } \\
\text { capital de su provincia }\end{array}$ & 80 & 192 & & & \\
\hline $\begin{array}{l}\text { Por } 15 \text { días anteriores a las sesiones a } 10 \text { soles } \\
\text { diarios. }\end{array}$ & & & 150 & & \\
\hline Por su mesada de establecimiento. & & & 300 & & \\
\hline Por sus dietas de 10 días hasta el 3 del presente & & & & 100 & 742 \\
\hline $\begin{array}{l}\text { Don Leopoldo Santolalla, diputado por Tumbes, a } \\
\text { la capital de su provincia }\end{array}$ & 136 & 326.4 & & & \\
\hline $\begin{array}{l}\text { Por } 15 \text { días anteriores y } 15 \text { posteriores a las } \\
\text { sesiones a } 10 \text { soles diarios. }\end{array}$ & & & 300 & & \\
\hline Por su mesada de establecimiento. & & & 300 & & 1306.1 \\
\hline $\begin{array}{l}\text { Por sus dietas en los } 38 \text { días calculados a } 10 \text { soles } \\
\text { diarios. }\end{array}$ & & & & 380 & \\
\hline $\begin{array}{l}\text { Don Manuel Revilla diputado por Chiclayo, a la } \\
\text { capital de su provincia }\end{array}$ & 47 & 112.8 & & & \\
\hline $\begin{array}{l}\text { Por } 15 \text { días anteriores y } 15 \text { posteriores a las } \\
\text { sesiones a } 10 \text { soles diarios. }\end{array}$ & & & 300 & & \\
\hline Por su mesada de establecimiento. & & & 300 & & \\
\hline $\begin{array}{l}\text { Por sus dietas en los } 38 \text { días calculados a } 10 \text { soles } \\
\text { diarios. }\end{array}$ & & & & 380 & 1072.8 \\
\hline $\begin{array}{l}\text { Don Salomón Rodríguez, diputado por Trujillo, a la } \\
\text { capital de su provincia }\end{array}$ & 45 & 108 & & & \\
\hline $\begin{array}{l}\text { Por } 15 \text { días anteriores a las sesiones a } 10 \text { soles } \\
\text { diarios. }\end{array}$ & & & 150 & & \\
\hline Por su mesada de establecimiento. & & & 300 & & \\
\hline $\begin{array}{l}\text { Por sus dietas en } 16 \text { días calculados a } 10 \text { soles } \\
\text { diarios. }\end{array}$ & & & & 160 & 718 \\
\hline $\begin{array}{l}\text { Don Santiago Vásquez, diputado por Chiclayo, a la } \\
\text { capital de su provincia }\end{array}$ & 47 & 112.8 & & & \\
\hline $\begin{array}{l}\text { Por } 15 \text { días anteriores y } 15 \text { posteriores a las } \\
\text { sesiones a } 10 \text { soles diarios. }\end{array}$ & & & 300 & & \\
\hline Por su mesada de establecimiento. & & & 300 & & \\
\hline $\begin{array}{l}\text { Por sus dietas en los } 38 \text { días calculados a } 10 \text { soles } \\
\text { diarios. }\end{array}$ & & & & 380 & 1072.8 \\
\hline $\begin{array}{l}\text { Don Manuel Fernando Pastor, diputado por } \\
\text { Trujillo, a la capital de su provincia }\end{array}$ & 49 & 108 & & & \\
\hline $\begin{array}{l}\text { Por } 15 \text { días anteriores y } 15 \text { posteriores a las } \\
\text { sesiones a } 10 \text { soles diarios. }\end{array}$ & & & 300 & & \\
\hline Por su mesada de establecimiento. & & & 300 & & \\
\hline $\begin{array}{l}\text { Por sus dietas en los } 35 \text { días desde el } 28 \text { de } \\
\text { diciembre hasta el } 31 \text { del presente calculados a } 10 \\
\text { soles diarios. }\end{array}$ & & & & 350 & 1058 \\
\hline $\begin{array}{l}\text { Don Francisco Placencia, diputado por Contumazá, } \\
\text { a la capital de su provincia }\end{array}$ & 49 & 36 & & & \\
\hline $\begin{array}{l}\text { Por } 15 \text { días anteriores y } 15 \text { posteriores a las } \\
\text { sesiones a } 10 \text { soles diarios. }\end{array}$ & & & 300 & & \\
\hline Por su mesada de establecimiento. & & & 300 & & \\
\hline $\begin{array}{l}\text { Por sus dietas en los } 23 \text { días calculados a } 10 \text { soles } \\
\text { diarios. }\end{array}$ & & & & 230 & 866 \\
\hline
\end{tabular}


Abanto

\begin{tabular}{|c|c|c|c|c|c|}
\hline Diputado de la Asamblea del Norte & $\begin{array}{c}\text { Total, de leguas } \\
\text { con respecto a } \\
\text { Cajamarca, sede de la } \\
\text { Asamblea del Norte } \\
\end{array}$ & $\begin{array}{l}\text { Pago por traslado } \\
\text { en leguas } \\
\text { recorridas }(*)\end{array}$ & Mesada & Dieta & Total \\
\hline & Soles & Soles & Soles & Soles & Soles \\
\hline $\begin{array}{l}\text { Don Gaspar López, diputado por Luya, a Lama, } \\
\text { capital de la referida provincia }\end{array}$ & 58 & 139.2 & & & \\
\hline $\begin{array}{l}\text { Por } 15 \text { días anteriores a las sesiones a } 10 \text { soles } \\
\text { diarios. }\end{array}$ & & & 150 & & \\
\hline Por su mesada de establecimiento. & & & 300 & & \\
\hline $\begin{array}{l}\text { Por sus dietas en los } 22 \text { días calculados a } 10 \text { soles } \\
\text { diarios. }\end{array}$ & & & & 220 & 809.2 \\
\hline $\begin{array}{l}\text { Don José Arana, diputado por Huari, la capital de } \\
\text { su provincia }\end{array}$ & 132 & 316.8 & & & \\
\hline $\begin{array}{l}\text { Por } 15 \text { días anteriores a las sesiones a } 10 \text { soles } \\
\text { diarios. }\end{array}$ & & & 150 & & \\
\hline Por su mesada de establecimiento. & & & 300 & & \\
\hline $\begin{array}{l}\text { Por sus dietas desde el } 12 \text { al } 31 \text { del presente } \\
\text { calculados a } 10 \text { soles diarios. }\end{array}$ & & & & 190 & 956.8 \\
\hline
\end{tabular}

(*) A razón de 2 soles y 40 centavos por legua, ida y regreso.

\section{Fuentes Documentales}

Serna, G (Cajamarca, 09 de mayo de 1882). Oficio del prefecto Guillermo Serna al jefe político militar del norte. (Legajo 251, serie Prefecturas). Archivo Regional de Cajamarca.

Serna, G (Cajamarca, 10 de mayo de 1882). Oficio del prefecto Guillermo Serna al jefe político militar del norte. (Legajo 251, serie Prefecturas). Archivo Regional de Cajamarca.

Serna, G (Cajamarca, 11 de junio de 1882). Oficio del prefecto Guillermo Serna al jefe político militar del norte. (Legajo 251, serie Prefecturas). Archivo Regional de Cajamarca.

Serna, G (Cajamarca, 14 de junio de 1882). Oficio del prefecto Guillermo Serna al jefe político militar del norte. (Legajo 251, serie Prefecturas). Archivo Regional de Cajamarca.

Serna, G (Cajamarca, 20 de junio de 1882). Oficio del prefecto Guillermo Serna al jefe político militar del norte. (Legajo 251, serie Prefecturas). Archivo Regional de Cajamarca.

Diario La Reacción (Cajamarca, 9 de marzo de 1882). Sin numeración. Sala para Investigadores de Manuscritos y Libros Raros de la Biblioteca Nacional del Perú.

Callirgos, M (Cajamarca, 24 de setiembre de 1882). Oficio del prefecto Manuel Callirgos a la subprefectura del Cercado de Cajamarca. (Legajo 07, serie Prefecturas). Archivo Regional de Cajamarca.

Callirgos, M (Cajamarca, 21 de noviembre de 1882). Oficio del prefecto Manuel Callirgos a la jefatura político militar del norte. (Legajo 251, serie Prefecturas). Archivo Regional de Cajamarca.

Iglesias, L (Cajamarca, 24 de abril de 1883). Oficio del ministro general Lorenzo Iglesias a los secretarios de la Asamblea del Norte. (Cuaderno copiador de correspondencia. CC 873). Archivo del Centro Histórico Militar del Perú

Asamblea del Norte (Cajamarca, 5 de enero de 1883). Ley aprobada. (Legajo. 222, sub-serie Impresos, serie Prefecturas). Archivo del Centro Histórico Militar del Perú. 
Iglesias, L (Cajamarca, 09 de enero de 1883). Oficio del ministro general Lorenzo Iglesias a los secretarios de la Asamblea del Norte. (Cuaderno copiador de correspondencia, CC 873). Archivo del Centro Histórico Militar del Perú.

Asamblea del Norte (Cajamarca, 19 de enero de 1883. Expediente sobre la erección del distrito de Huacapampa, provincia de Celendín, Cajamarca. (Código de barras 20000010624). Sala para Investigadores de Manuscritos y Libros Raros de la Biblioteca Nacional del Perú.

Asamblea del Norte (Cajamarca, 13 de febrero de 1883). Ley expedida por la soberana asamblea del norte elevando al rango de distrito el caserío de Huacapampa, provincia de Celendín. (Código de barras 2000010784). Sala para Investigadores de Manuscritos y Libros Raros de la Biblioteca Nacional del Perú.

Iglesias, L (Cajamarca, 12 de abril de 1883). Oficio del ministro general Lorenzo Iglesias a los secretarios de la Asamblea del Norte. (Cuaderno copiador de correspondencia, CC 873). Archivo del Centro Histórico Militar del Perú.

Secretaría General de Estado (Lima, 17 de enero de 1880). Oficio de la Secretaría General de Estado a Luis Milón Duarte. (Cuaderno copiador de correspondencia, CC 526). Archivo del Centro Histórico Militar del Perú.

Asamblea del Norte (Cajamarca, 19 de enero de 1883). Expediente sobre la acusación formulada contra el coronel Julio Hernández, exdiputado por la provincia de Piura por haber escrito un manifiesto contrario al sentir de la Asamblea Nacional. (Código de barras $N^{\circ}$ 2000010625). Sala para Investigadores de Manuscritos y Libros Raros de la Biblioteca Nacional del Perú.

Iglesias, L (Cajamarca, 01 de febrero de 1883). Oficio del ministro general Lorenzo Iglesias a los secretarios de la Asamblea del Norte. (Cuaderno copiador de correspondencia, CC 873). Archivo del Centro Histórico Militar del Perú.

Iglesias, L (Cajamarca, 19 de enero de 1883). Oficio del ministro general Lorenzo Iglesias a los secretarios de la Asamblea del Norte. (Cuaderno copiador de correspondencia, CC 873). Archivo del Centro Histórico Militar del Perú.

Iglesias, L (Cajamarca, 14 de marzo de 1883). Oficio del ministro general Lorenzo Iglesias a los secretarios de la Asamblea del Norte. (Cuaderno copiador de correspondencia, CC 873). Archivo del Centro Histórico Militar del Perú.

Iglesias, L (Cajamarca, 02 de abril de 1883). Oficio del ministro general Lorenzo Iglesias a los secretarios de la Asamblea del Norte. (Cuaderno copiador de correspondencia, CC 873). Archivo del Centro Histórico Militar del Perú.

Iglesias, L (Cajamarca, 01 de mayo de 1883). Oficio del ministro general Lorenzo Iglesias a los secretarios de la Asamblea del Norte. (Cuaderno copiador de correspondencia, CC 873). Archivo del Centro Histórico Militar del Perú.

Iglesias, L (Cajamarca, 09 de abril de 1883). Oficio del ministro general Lorenzo Iglesias a los secretarios de la Asamblea del Norte. (Cuaderno copiador de correspondencia, CC 873). Archivo del Centro Histórico Militar del Perú.

Iglesias, L (Cajamarca, 26 de febrero de 1883). Oficio del ministro general Lorenzo Iglesias a los secretarios de la Asamblea del Norte. (Cuaderno copiador de correspondencia, CC 873). Archivo del Centro Histórico Militar del Perú. 


\section{Congreso de la República}

\section{Archivo Digital de Legislación Peruana}

Legislación del siglo XIX hasta 1904. Leyes de 1879, 1880, 1882, 1883.

http://www.congreso.gob.pe/ntley/default.asp

II. Archivo General del Congreso

http://www.congreso.gob.pe/archivo/funciones.html

III. Mensajes presidenciales 1821 - 2010

http://www.congreso.gob.pe/museo.htm

\section{Presidentes del Congreso}

http://www4.congreso.gob.pe/museo/presidentes.html

\section{Bibliografía}

Abanto, J. (2012) Encarando el desastre. El conflicto hegemónico entre la burguesía limeña y los terratenientes serranos del norte (1881-1884). Lima: Universidad Nacional Mayor de San Marcos.

Ahumada, P. (1898). Guerra del Pacífico. Recopilación completa de todos los documentos oficiales, correspondencias y demás publicaciones que ha dado a luz la prensa de Chile, Perú y Bolivia, conteniendo documentos inéditos de importancia. Tomos V-VIII. Valparaíso: Editorial Mercurio.

Anónimo (1886). El doctor José Mercedes Puga y su participación en los sucesos del norte. Lima: Imprenta Torres Aguirre.

Basadre, J. (1964). Historia de la República. Tomo. VIII. Lima: Editorial Universitaria.

Bulnes, G. (1919). Guerra del Pacífico. Tomo III. Valparaíso: Universo.

Cáceres, A. (1973). La guerra del 79: sus campañas (memorias). Lima: Editorial Milla Batres.

Congreso de la República (1836). Mensajes Presidenciales. Museo del Congreso y la Inquisición. Recuperado en junio de 2015. http://www4.congreso.gob.pe/museo/mensajes/a-Mensaje-1836-8.asp

Congreso de la República (1882). Mensajes Presidenciales. Museo del Congreso y la Inquisición. Recuperado en junio de 2015. http://www.congreso.gob.pe/museo.htm

Congreso de la República (1883). Memoria que el Secretario General de la Jefatura del Norte, Coronel Julio S. Hernández, presenta a la Asamblea de Representantes Provinciales, reunida en Cajamarca, el 5 de enero de 1883. Mensajes Presidenciales. Museo del Congreso y la Inquisición. Recuperado en junio de 2015, de http:// www.congreso.gob.pe/museo.htm

Congreso de la República (2015). Archivo Digital de Legislación Peruana. Recuperado en junio de 2015. http:// www.congreso.gob.pe/ntley/default.asp.

Congreso de la República (1998). El Poder Legislativo y sus representantes. 1822-2000. Colección Documental. Lima: Congreso de la República.

Dammert, J. (1983). Cajamarca durante la guerra del Pacífico. Cajamarca: Impresiones MACS.

Guerrero, J. C. (1975). 1879-1883: La guerra de las ocasiones perdidas. Lima: Editorial Milla Batres.

Lynch, P. (1882). Primera Memoria que el General en Jefe del Ejército de Operaciones en el Norte del Perú presenta al Supremo Gobierno de Chile. Lima: Imprenta Calle. 
Lynch, P. (1884). Segunda Memoria que el General en Jefe del Ejército de Operaciones en el Norte del Perú presenta al Supremo Gobierno de Chile. Lima: Imprenta de La Merced.

Mc Evoy, C. (2016). Chile en el Perú. La ocupación a través de sus documentos 1881-1884.Lim: Fondo Editorial del Congreso de la República.

Mallon, F. (2003). De ciudadano a “otro". Resistencia nacional, formación del estado y visiones campesinas sobre la nación en Junín. Revista Andina, 1(12): 7-78. Cusco: Centro de estudios Regionales andinos Bartolomé de Las Casas.

Mallon, F. (2003). Campesino y nación: la construcción de México y Perú poscoloniales. México D.F.: El Colegio de San Luis.

Manrique, N. (1981). Campesinado y nación: Las guerrillas indígenas en la guerra con Chile. Lima: Centro de Investigación y Capacitación.

Manrique, N. (1988). Yawar Mayu: sociedades terratenientes serranas, 1879-1910. Lima: Instituto Francés de Estudios Andinos, Centro de Estudios y Promoción del Desarrollo.

Puente Candamo, J. y Puente Brunke J. (editores) (2008). El Perú desde la intimidad. Epistolario de Manuel Candamo (1873-1904). Lima: Pontificia Universidad Católica del Perú.

Ravines, R. (1992). Partes oficiales en la Guerra del Pacífico. 1880-1882. Lima: Editorial Los Pinos.

Tuesta Soldevilla, F. (2011). Perú Político en cifras. 1821 - 2001. Tercera edición. Lima: Fundación Friedrich Ebert.

Ugarte del Pino, J. V. (1978). Historia de las Constituciones del Perú. Lima: Editorial Andina.

Presentado: 30 mayo 2017

Aceptado: 6 febrero 2018

Publicado online: 11 julio 2018 
